University of Nebraska - Lincoln

DigitalCommons@University of Nebraska - Lincoln

\title{
Inverse modeling of BTEX dissolution and biodegradation at the Bemidji, MN crude-oil spill site
}

\author{
Hedeff I. Essaid \\ U.S. Geological Survey \\ Isabelle M. Cozzarelli \\ U.S. Geological Survey \\ Robert P. Eganhouse \\ U.S. Geological Survey \\ William N. Herkelrath \\ U.S. Geological Survey \\ Barbara A. Bekins \\ U.S. Geological Survey \\ See next page for additional authors
}

Follow this and additional works at: https://digitalcommons.unl.edu/usgsstaffpub

Part of the Earth Sciences Commons

Essaid, Hedeff I.; Cozzarelli, Isabelle M.; Eganhouse, Robert P.; Herkelrath, William N.; Bekins, Barbara A.; Delin, Geoffrey N.; and Butler, Win, "Inverse modeling of BTEX dissolution and biodegradation at the Bemidji, MN crude-oil spill site" (2003). USGS Staff -- Published Research. 212.

https://digitalcommons.unl.edu/usgsstaffpub/212

This Article is brought to you for free and open access by the US Geological Survey at DigitalCommons@University of Nebraska - Lincoln. It has been accepted for inclusion in USGS Staff -- Published Research by an authorized administrator of DigitalCommons@University of Nebraska - Lincoln. 


\section{Authors}

Hedeff I. Essaid, Isabelle M. Cozzarelli, Robert P. Eganhouse, William N. Herkelrath, Barbara A. Bekins, Geoffrey N. Delin, and Win Butler 


\title{
Inverse modeling of BTEX dissolution and biodegradation at the Bemidji, MN crude-oil spill site
}

\author{
Hedeff I. Essaid ${ }^{\mathrm{a}, *}$, Isabelle M. Cozzarelli ${ }^{\mathrm{b}}$, Robert P. Eganhouse ${ }^{\mathrm{b}}$, \\ William N. Herkelrath ${ }^{\mathrm{a}}$, Barbara A. Bekins ${ }^{\mathrm{a}}$, Geoffrey N. Delin ${ }^{\mathrm{c}}$ \\ ${ }^{a}$ U.S. Geological Survey, 345 Middlefield Road, MS 496, Menlo Park, CA 94025, USA \\ ${ }^{\mathrm{b}}$ U.S. Geological Survey, 432 National Center, 12201 Sunrise Valley Drive, Reston, VA 20192, USA \\ ${ }^{\mathrm{c}}$ U.S. Geological Survey, 2280 Woodale Drive, Mounds View, MN 55112, USA
}

Received 15 March 2002; accepted 17 February 2003

\begin{abstract}
The U.S. Geological Survey (USGS) solute transport and biodegradation code BIOMOC was used in conjunction with the USGS universal inverse modeling code UCODE to quantify field-scale hydrocarbon dissolution and biodegradation at the USGS Toxic Substances Hydrology Program crude-oil spill research site located near Bemidji, MN. This inverse modeling effort used the extensive historical data compiled at the Bemidji site from 1986 to 1997 and incorporated a multicomponent transport and biodegradation model. Inverse modeling was successful when coupled transport and degradation processes were incorporated into the model and a single dissolution rate coefficient was used for all BTEX components. Assuming a stationary oil body, we simulated benzene, toluene, ethylbenzene, $m, p$-xylene, and $o$-xylene (BTEX) concentrations in the oil and ground water, respectively, as well as dissolved oxygen. Dissolution from the oil phase and aerobic and anaerobic degradation processes were represented. The parameters estimated were the recharge rate, hydraulic conductivity, dissolution rate coefficient, individual first-order BTEX anaerobic degradation rates, and transverse dispersivity. Results were similar for simulations obtained using several alternative conceptual models of the hydrologic system and biodegradation processes. The dissolved BTEX concentration data were not sufficient to discriminate between these conceptual models. The calibrated simulations reproduced the general large-scale evolution of the plume, but did not reproduce the observed small-scale spatial and temporal variability in concentrations. The estimated anaerobic biodegradation rates for toluene and $o$-xylene were greater than the dissolution rate coefficient. However, the estimated anaerobic biodegradation rates for benzene, ethylbenzene, and $m, p$-xylene were less than the dissolution rate coefficient. The calibrated model was used to determine the BTEX mass balance in the oil body and groundwater plume.
\end{abstract}

* Corresponding author. Tel.: +1-650-329-4581; fax: +1-650-329-4463.

E-mail address: hiessaid@usgs.gov (H.I. Essaid). 
Dissolution from the oil body was greatest for compounds with large effective solubilities (benzene) and with large degradation rates (toluene and $o$-xylene). Anaerobic degradation removed $77 \%$ of the BTEX that dissolved into the water phase and aerobic degradation removed $17 \%$. Although goodness-of-fit measures for the alternative conceptual models were not significantly different, predictions made with the models were quite variable.

(C) 2003 Elsevier Science B.V. All rights reserved.

Keywords: Biodegradation; Dissolution; Modeling; Hydrocarbons; BTEX; Natural attenuation

\section{Introduction}

The natural attenuation of hydrocarbons in ground water has been well documented by many field studies. Numerical models that simulate transport and biodegradation processes have been used in conjunction with field data to assess natural attenuation (National Research Council, 2000). Models can be used to integrate information collected in the field, quantify contaminant mass balance, quantify attenuation rates, and to study the relative importance of simultaneously occurring processes. Field sampling limitations make it difficult to develop accurate mass balances for contaminants, and thus to distinguish the amount and rate of removal by biodegradation versus dilution and sorption. If sufficient data are available, a numerical model can be used to test conceptual models, quantify the processes contributing to natural attenuation, and predict plume evolution.

Models differ in the complexity by which they represent: (1) physical, chemical, and biological processes; (2) spatial and temporal variability; (3) source-term representation; and (4) solution approach. Detailed comprehensive modeling of natural attenuation of hydrocarbon fate is still limited by computational constraints, lack of comprehensive field data, and our lack of understanding of field-scale processes. Given these constraints, the level of model complexity that can be supported by field studies needs to be assessed.

Aerobic and anaerobic hydrocarbon biodegradation rates have been determined in many studies using laboratory microcosms, in situ field microcosms, and observed hydrocarbon concentration distributions at sites undergoing natural attenuation (Krumholz et al., 1996). The rate of dissolution from a nonaqueous phase has been studied in laboratory experiments (Powers et al., 1994), and in numerical studies at the pore scale (Dillard and Blunt, 2000; Held and Celia, 2001) and field scale (Frind et al., 1999; Zhu and Sykes, 2000; Dillard et al., 2001). Our knowledge of multicomponent field-scale dissolution influenced by biodegradation is limited (Khachikian and Harmon, 2000) although recent studies have examined this issue in column experiments (Seagren et al., 1993; Yang and McCarty, 2002).

Many studies of hydrocarbon attenuation at field sites have involved numerical modeling (Borden et al., 1986; Rifai et al., 1988; Chiang et al., 1989; MacQuarrie et al., 1990; Thierrin et al., 1993; Essaid et al., 1995; Landmeyer et al., 1996; Lu et al., 1999; Schirmer et al., 2000). In general, these models have had limited data sets, have not included dissolution processes, and have relied on trial and error calibration. As model and hydrologic system complexity increase, trial-and-error calibration becomes very difficult 
and highly uncertain. Formal inverse modeling facilitates objective determination of model parameters that produce the best possible fit to available observations, quantification of the quality of fit, and quantification of the reliability of parameter estimates (Hill, 1998). Inverse modeling can also be used to diagnose inadequate data, identify parameters that cannot be estimated with the given data set, evaluate the conceptual model representation, and quantify the uncertainty of model simulated values. Inverse modeling has been used for hydrocarbon and dense nonaqueous phase liquid source identification (Parker and Islam, 2000; Sciortino et al., 2000), estimating biodegradation rates in batch experiments (Schirmer et al., 1999), and evaluating biodegradation rates of chlorinated ethenes in a fractured dolomite aquifer near Niagara Falls, NY (Yager, 2000).

In this study, the extensive historical data collected at the Bemidji site from 1986 to 1997 were fit using inverse modeling to estimate field-scale biodegradation and dissolution rates. A simplified representation of dissolution that does not require multiphase flow modeling was used to make inverse modeling computationally feasible.

\subsection{Inverse modeling of the Bemidji crude oil spill site}

On August 20, 1979, a buried oil pipeline located in a pitted and dissected glacial outwash plain near Bemidji, MN, broke, spilling about $1.7 \times 10^{6} 1$ (11,000 barrels) of crude oil. The petroleum in the pipeline was under pressure, causing the oil to be sprayed over approximately $6500 \mathrm{~m}^{2}$. An estimated $1.2 \times 10^{6} 1$ (7800 barrels) of the spilled oil was removed by pumping from surface pools, trenching, burning, and excavation of soil (Hult, 1984). The oil collected in topographic depressions and trenches where oil subsequently infiltrated into the subsurface. Depth to the water table ranges from 0 to $8 \mathrm{~m}$ below land surface and water levels fluctuate about $0.5 \mathrm{~m}$ seasonally. The subsurface oil body is a long-term, continuous source of hydrocarbon components that dissolve in, and are transported with the flowing ground water.

In a previous modeling effort (Essaid et al., 1995), a numerical model incorporating sequential use of terminal electron acceptors was used to analyze the evolution of the ground-water contaminant plume at the Bemidji site. The model was based on field observations that provided substantial evidence for the sequential use of electron acceptors (Baedecker et al., 1993; Cozzarelli et al., 2001, Bekins et al., 2001). Essaid et al. (1995) included relatively complex representations of sequential biodegradation processes, but simple substrate and source representations. The plume was represented by two operationally defined degradable fractions-volatile dissolved organic carbon (VDOC) and nonvolatile dissolved organic carbon (NVDOC). However, evidence suggests that individual hydrocarbon compounds degrade at different rates (Eganhouse et al., 1993a, 1996). Also, the model used a simple source representation that did not account for dissolution of hydrocarbons from the oil body, and trial-and-error was used to calibrate the model.

In this modeling study we considered individual BTEX compounds and included dissolution from the oil body, transport, and biodegradation. Simplified representations of biodegradation and dissolution processes, involving as few parameters as possible, were used to facilitate inverse modeling. Given the complexity of the observed concentration distributions and model parameters, trial-and-error calibration of the model was not 
practical. Inverse modeling was used to calibrate the model of BTEX fate at the Bemidji site. The calibrated model was used to:

1. evaluate the effectiveness of inverse modeling of a complex system with coupled processes using a data set containing significant spatial and temporal variability, and test the ability to evaluate alternative conceptual models of the system;

2. estimate the field-scale dissolution and anaerobic biodegradation rates of the BTEX compounds, and to compare with field estimates obtained using standard analytical protocols and published literature values;

3. evaluate BTEX removal from the oil body by dissolution, BTEX removal from the ground-water plume by aerobic and anaerobic biodegradation, and evaluate the influence of biodegradation on dissolution.

\subsection{Available data}

The data used in this study included a total of 1072 measurements of benzene, toluene, ethylbenzene, $m, p$-xylene (coeluting $m$ - and $p$-xylenes), and $o$-xylene (BTEX) and oxygen concentrations from 30 wells and 55 core sections, 117 oil saturation measurements, and three oil samples (Fig. 1). Ground-water samples from numerous wells along a transect parallel to the direction of groundwater flow (Fig. 1) were analyzed over time (Baedecker et al., 1993; Bennett et al., 1993; Eganhouse et al., 1993a). Purge-and-trap capillary gas chromatography was used to measure BTEX concentrations (Eganhouse et al., 1993b). This method could not resolve $m$ - and $p$-xylene concentrations because they coeluted.

Concentrations of BTEX and dissolved oxygen were measured in wells annually from 1986 until 1995 (except for 1989, 1991, and 1994). In general, water table wells had 1.5-m long screens and deeper wells had 0.15-m long screens (Fig. 1). Methods were later developed to extract water from cores collected from the subsurface allowing porewater concentration measurements at the $0.15-\mathrm{m}$ scale in 1992, 1993, 1995, 1996, and 1997 (Cozzarelli et al., 2001). The locations of the screened intervals of the monitoring wells and the core concentration measurements used in this study are shown in Fig. 1.

In 1990 and 1992 cores were collected from 10 locations (Fig. 1) and analyzed using the methods of Hess et al. (1992) to determine oil saturation. At each core sampling location, oil saturation was determined for $0.075 \mathrm{~m}$ subsections. The core sections were used to characterize the subsurface oil saturation distribution.

In 1987, Eganhouse et al. (1996) collected three oil samples from locations $35 \mathrm{~m}$ upgradient of the center of the oil body, at the center of the oil body (Well 421), and $25 \mathrm{~m}$ downgradient from the center of the oil body. The elevation and oil saturation of the samples was not determined at the time of collection. The equilibrium water phase monoaromatic hydrocarbon concentrations obtained from oil-water equilibration experiments were used to determine the fraction of each compound in the oil. This varied from the upgradient to the downgradient part of the oil body, with the highest values generally being in the least weathered core of the oil body (Eganhouse et al., 1996).

A bromide tracer test was conducted in August 1997 between two wells $1.6 \mathrm{~m}$ apart to obtain an estimate of ground-water flow velocities. The injection well was located $57 \mathrm{~m}$ downgradient of Well 421. Fitting the analytical solution for an instantaneous point source 
Map

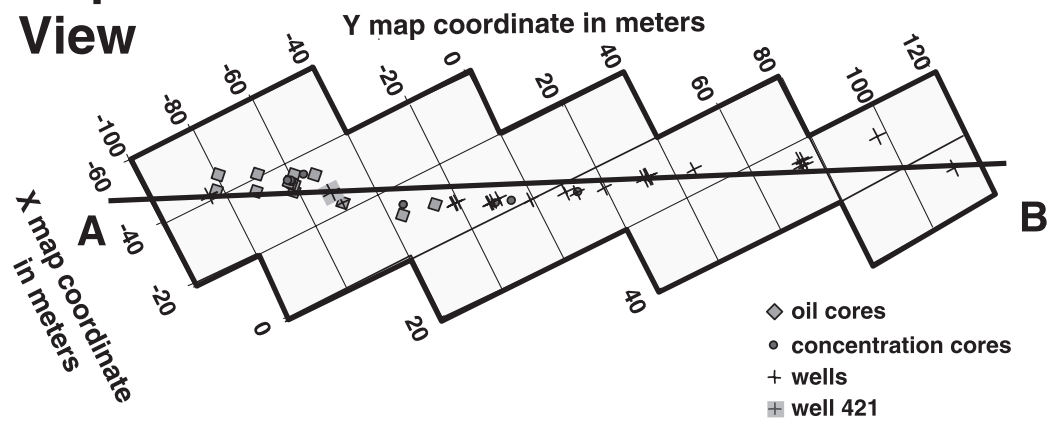

Cross-sectional View

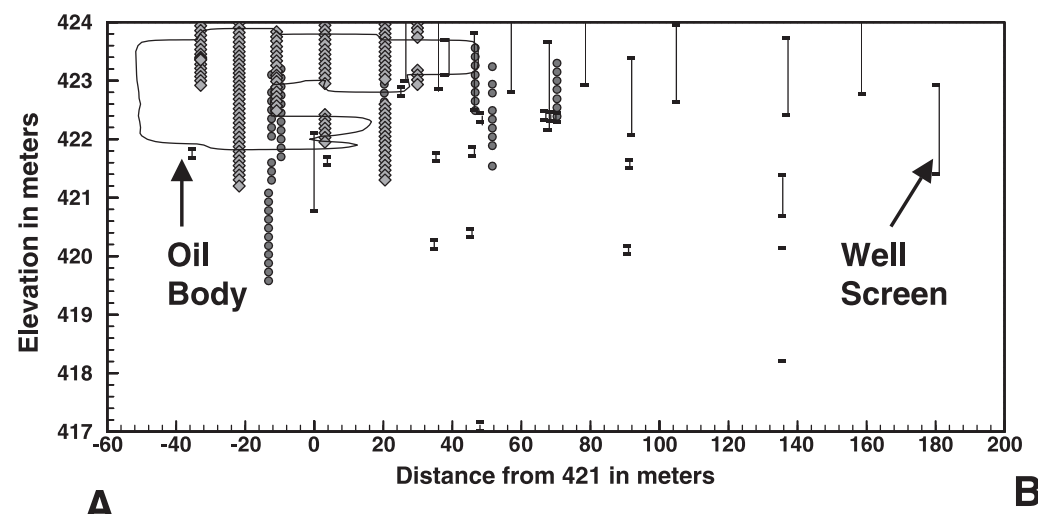

Fig. 1. Locations of data used in model formulation.

with three-dimensional dispersion in a uniform flow field (Freeze and Cherry, 1979) assuming that the observations fell along the plume centerline yielded a flow velocity of $0.06 \mathrm{~m} \mathrm{day}^{-1}$, and an estimated longitudinal dispersivity of $0.15 \mathrm{~m}$. This estimate agrees well with tracer test velocity estimates made at other locations at the site (G. Curtis, USGS, personal communication).

Recharge rates at the site have been estimated using several techniques (Delin and Herkelrath, 1999; Herkelrath and Delin, 2001). Using soil-moisture measurements, Herkelrath and Delin (2001) obtained recharge estimates ranging from 0.2 to $0.3 \mathrm{~m} /$ year. Average annual recharge estimates obtained by using water-level rises observed in hydrographs throughout the area and assuming a specific yield of 0.3 ranged from 0.1 to $0.2 \mathrm{~m} /$ year. Tritium/helium based recharge estimates ranged from 0.07 to $0.14 \mathrm{~m} / \mathrm{year}$.

\section{Basic conceptual model}

The basic conceptual model of the Bemidji site included: rate-controlled dissolution of benzene, toluene, ethylbenzene, $m, p$-xylene, and $o$-xylene (BTEX) from a stationary oil 
phase; first-order anaerobic degradation of dissolved BTEX and first-order aerobic degradation of dissolved BTEX. The main assumptions of the simulations were (1) steady-state water flow with constant uniform recharge, (2) an oil phase saturation distribution that did not change with time, (3) temporally and spatially uniform biodegradation rates, and (4) a single uniform dissolution rate coefficient for all hydrocarbons. The experiments of Burris and MacIntyre (1986) demonstrated that multicomponent non-aqueous phase hydrocarbon mixtures in contact with water resulted in nonequilibrium hydrocarbon solute concentration ratios that were close to those found at equilibrium. Their results support the assumption of a single dissolution coefficient for mixtures of hydrocarbons.

The 11 concentrations simulated in the model included the five immobile oil phase BTEX concentrations, and the six mobile dissolved phase concentrations of BTEX and oxygen. The reactions represented in the model included the dissolution of BTEX with subsequent change in oil phase BTEX concentrations, and anaerobic and aerobic degradation of dissolved BTEX.

\subsection{BIOMOC flow and transport model}

BIOMOC (Essaid and Bekins, 1997) is a two-dimensional, multispecies reactive solutetransport model with sequential aerobic and anaerobic degradation processes. Transport is simulated using the particle-based Method of Characteristics (Konikow and Bredehoeft, 1978). The model allows for multiple particle sets; each particle set is capable of representing multiple solute species with similar sorption characteristics. The model design is general and flexible, permitting simulation of biotransformation reactions for any combination of electron donor and acceptor. The degradation reaction rate is represented by Monod kinetics (Monod, 1949), but approximations to first-order or zero-order reactions can be made.

The first-order reaction approximation for the multiple Monod biodegradation kinetics formulation option of BIOMOC was used to represent all reactions by setting $K_{1}^{n}=K_{2}^{n}=K_{m}^{n} \gg C_{m}$ so that for the $n$th biodegradation process involving $m$ solutes:

$$
V^{n}=\frac{V_{\max }^{n}}{K_{1}^{n} I_{\mathrm{nc}}} X_{k}^{n}\left(C_{1} C_{2} \ldots C_{m}\right)
$$

where $V^{n}$ is the uptake rate of substrate by biodegradation process $n\left(\mathrm{ML}^{-3} \mathrm{~T}^{-1}\right), V_{\max }^{n}$ is the asymptotic maximum specific uptake rate of the substrate $\left(\mathrm{T}^{-1}\right), I_{\mathrm{nc}}=1+Q_{s} / k_{s}$ is the noncompetitive inhibition factor, $Q_{s}$ is the concentration of the inhibiting solute $s\left(\mathrm{ML}^{-3}\right)$, $k_{s}$ is the inhibition constant for solute $s\left(\mathrm{ML}^{-3}\right), K_{m}^{n}$ is the half-saturation constant for the $m$ th solute ( $\left.\mathrm{ML}^{-3}\right), C_{m}$ is the concentration of the $m$ th solute involved in the process, and $X_{k}^{n}$ is the biomass concentration of microbial population $k$ responsible for biodegradation process $n\left(\mathrm{ML}^{-3}\right)$. No biomass growth was allowed making first-order decay rate coefficients constant in time and space.

Each solute may be involved in several biodegradation processes. The total uptake of any solute $i$ is the summation of the uptake for all simultaneously occurring processes:

$$
B_{i}=\sum_{n=1}^{N} \beta_{i}^{n} V^{n}
$$


where $N$ is the total number of biodegradation processes and $\beta_{i}^{n}$ is the uptake coefficient of solute $i$ for biodegradation process $n$. When the solute is the primary substrate, $\beta_{i}^{n}$ is equal to 1 . Otherwise, $\beta_{i}^{n}$ is determined by the stoichiometry of the reaction and is equal to the ratio of the mass uptake of solute $i$ to that of the primary substrate. The value of $\beta_{i}^{n}$ is negative if the solute is produced by the $n$th biodegradation process and is 0 if the solute is not involved in the biodegradation process.

\subsubsection{Flow initial and boundary conditions}

A vertical cross-section (14 m deep, $260 \mathrm{~m}$ wide, unit width) parallel to the direction of ground-water flow was simulated from the time of the spill in 1979 until September 1997. The upper half of the simulated section is shown in Fig. 2. The unsaturated zone above the modeled cross-section was 3-5 m thick. Because temperature fluctuations are attenuated in this zone, isothermal conditions could be assumed. The average organic carbon content of the aquifer is $0.09 \%$ (Baedecker et al., 1993), resulting in a very small retardation factor estimate. Therefore, sorption processes were neglected. A 2-m horizontal and 0.1-m vertical discretization grid was used. Constant heads of 424.0 and $423.1 \mathrm{~m}$ were specified along the upgradient and downgradient boundaries, respectively, reproducing the observed average water table gradient of $0.0035 \mathrm{~m} / \mathrm{m}$. The no-flow bottom boundary was placed deep enough so that heads and concentrations were not influenced by it. The cross-section was assumed to have a uniform constant recharge rate and uniform hydraulic conductivity that were determined during the calibration process.

Immediately after the oil spill there was rapid oil infiltration and redistribution. However, field observations since 1986 suggest that there is only some small vertical movement of the oil in response to $0.5-\mathrm{m}$ seasonal water-table fluctuations, and a very slow advance of the leading edge of the oil body. To simplify the modeling procedure, it

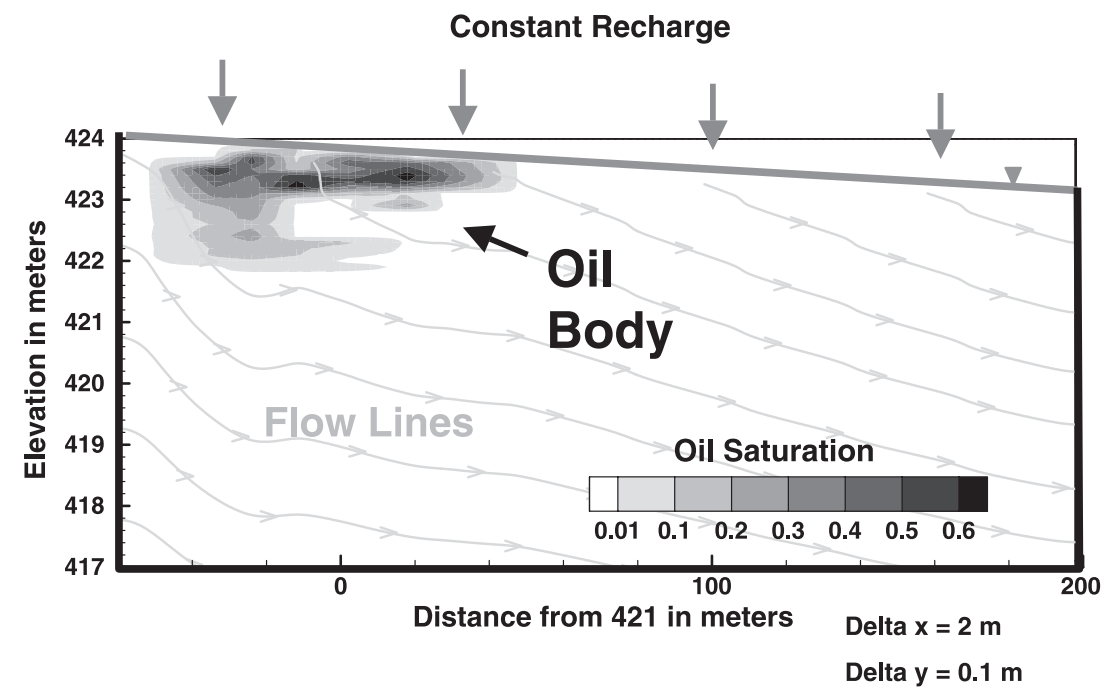

Fig. 2. Upper half of the modeled cross-section showing oil saturation distribution and flow lines. 
was assumed that the spatial distribution of the oil phase was relatively stationary. The slow movement of the oil phase was neglected and it was assumed that the observed concentration history of the plume (1986-1997) could be reproduced using an average stationary oil phase distribution determined from the oil saturation measurements made in 1990 and 1992.

The presence of oil in the pore space reduces the flow of water through the oil body zone. The magnitude of this reduction is a function of the oil saturation $\left(S_{\mathrm{o}}\right)$ and is represented by the water relative permeability $\left(k_{\mathrm{rw}}\right)$. The 117 oil saturation measurements were used to determine the oil saturation distribution in the oil body (Fig. 2). Linear interpolation was used to estimate oil saturations between the oil-saturation measurement locations. At locations that were sampled in 1990 and 1992, the cores from the sampling year that recovered the largest amount of oil were used in the interpolation.

The $k_{\mathrm{rw}}$ distribution in the zone of the oil body was calculated using the water saturation $\left(S_{\mathrm{w}}=1-S_{\mathrm{o}}\right)$ distribution and the two-phase flow relative permeability expression of Parker et al. (1987):

$$
k_{\mathrm{rw}}=S_{\mathrm{w}}^{0.5}\left(1-\left(1-S_{\mathrm{w}}^{1 / m}\right)^{m}\right)^{2}
$$

where $m=(1-(1 / n))$, and $n$ is a pore-size distribution parameter. An average value of $n$ of 3.98 was estimated using observed particle-size distributions and the methods of Essaid et al. (1993) and Dillard et al. (1997). Water relative permeabilities ranged from 0.02 in the highest oil saturation core of the oil body to close to 1.0 in the low oil saturation edges of the oil body. The effect of reduced water relative permeability in the oil zone is observed in the deflection of water flow lines around the oil body (Fig. 2). We neglected the change in oil saturation due to dissolution, and assumed steady flow through the oil body.

\subsubsection{Transport initial and boundary conditions}

The oil body is the source of BTEX compounds dissolved in the ground water plume. The oil saturation distribution and oil-phase mole fraction of each compound were used to calculate the initial BTEX concentrations in the immobile oil phase. Assuming ideal conditions, the mole fraction of the compound in the oil $\left(M_{\mathrm{O}_{i}}\right)$ equals:

$$
M_{\mathrm{O}_{i}}=\frac{C_{\mathrm{eff}_{i}}}{C_{\text {pure }_{i}}}
$$

where $C_{\text {eff }_{i}}$ effective solubility of component $i$ and $C_{\text {pure }_{i}}=$ pure phase solubility of component $i$. For the purposes of modeling, and because the original oil composition was unknown, the highest measured concentration of each compound in the equilibration experiments of Eganhouse et al. (1996) was assumed to be the effective solubility of the component. The effective solubilities used in the model were: benzene $10.6 \mathrm{mg} / \mathrm{l}$; toluene $4.21 \mathrm{mg} / \mathrm{l}$; ethylbenzene $0.524 \mathrm{mg} / \mathrm{l} ; \mathrm{m}, p$-xylene $1.26 \mathrm{mg} / \mathrm{l}$; and $o$-xylene $0.713 \mathrm{mg} / \mathrm{l}$. These effective solubilities and published values of pure-phase BTEX solubilities were used to calculate the mole fraction of each component in the unweathered oil phase. Using the oil saturation and mass fraction, the initial distribution of the mass of BTEX was 
calculated and used to obtain an equivalent immobile phase concentration for each grid block of the model containing oil:

$$
C_{\mathrm{o}_{i}}=10^{6} M_{\mathrm{o}_{i}} \rho_{\mathrm{o}} \frac{S_{\mathrm{o}}}{\left(1-S_{\mathrm{o}}\right)}
$$

where $\mathrm{C}_{\mathrm{o}_{i}}$ =initial immobile phase concentration of component $i$ in $\mathrm{mg} / \mathrm{l}, S_{\mathrm{o}}=$ oil saturation, and $\rho_{\mathrm{o}}=$ oil density in $\mathrm{gm} / \mathrm{cm}^{3}=0.854 \mathrm{gm} / \mathrm{cm}^{3}$ (Essaid et al., 1993). BIOMOC is not a multiphase flow and transport model and all concentrations are associated with the volume of water in the pore space. Therefore, the immobile phase concentration must be adjusted to represent mass per volume of water. The expression in Eq. (5) is equivalent to the mass of component $i$ in the oil phase in a model grid block divided by the volume of water in the model grid block. Combining Eqs. (4) and (5) and rearranging:

$$
C_{\mathrm{eff}_{i}}=\frac{C_{\mathrm{o}_{i}}\left(1-S_{\mathrm{o}}\right)}{10^{6} \rho_{\mathrm{o}} S_{\mathrm{o}}} C_{\text {pure }_{i}} .
$$

Assuming that $\rho_{\mathrm{o}}$ and $S_{\mathrm{o}}$ stay relatively constant during dissolution, because BTEX is a very tiny fraction of the total oil phase (Eganhouse et al., 1993b), the effective solubility of each hydrocarbon component will change with time as it dissolves from the oil phase and $C_{\mathrm{o}_{i}}$ changes.

The initial conditions for the simulation were zero dissolved BTEX concentrations and fully oxygenated water. The background dissolved oxygen concentration was $7.68 \mathrm{mg} / \mathrm{l}$ (Baedecker et al., 1993). Soil gas concentration measurements made by Hult et al. (1991) and Chaplin et al. (2002) have shown that biodegradation in the unsaturated zone depletes oxygen resulting in an anoxic unsaturated zone above the oil body. Therefore, it was assumed that there was no oxygen in the recharge water entering above the oil body and fully oxygenated recharge water in all other areas. Also, water entering across the upper $1.4 \mathrm{~m}$ of the upgradient boundary was assigned a reduced oxygen concentration of $4 \mathrm{mg} / \mathrm{l}$ corresponding to concentrations in upgradient water table wells. This zone has reduced oxygen concentrations due to aerobic biodegradation of hydrocarbon sprayed on the upgradient land surface at the time of the spill. All other water entering the aquifer was assumed to have the fully oxygenated concentration of $7.68 \mathrm{mg} / \mathrm{l}$. Finally, at discharging constant head boundaries it was assumed that $\delta C / \delta x=0$.

Residual oil is present in the unsaturated zone above the oil body and hydrocarbons dissolve in recharge water during infiltration. Chaplin et al. (2002) have shown that significant biodegradation takes place in the unsaturated zone and capillary fringe prior to reaching the water table. Total gas hydrocarbon concentrations in the unsaturated zone immediately above the oil body have decreased significantly from 1985-1997 suggesting relatively low hydrocarbon concentrations in the recharge water. Therefore, for the purposes of this analysis, it was assumed that recharge water contained no hydrocarbons. To test the influence of this assumption a simulation was carried out assuming the recharge water was contaminated with equilibrium BTEX concentrations and results were compared to the uncontaminated recharge water simulation. Contaminated recharge had little effect on the overall ground-water plume because the hydrocarbons were rapidly degraded 
near the water table and the BTEX mass input was small compared to the BTEX mass dissolving from the oil body.

\subsubsection{Reactions}

The basic simulation was set up with five immobile phase concentrations representing BTEX present in the oil, and six mobile solutes representing BTEX and dissolved oxygen concentrations in the ground water. The dissolution of each component from the oil $\left(J_{i}\right)$ was represented by the sum of two first order reactions:

$$
J_{i}=K_{\text {diss }}\left(C_{\text {eff }_{i}}-C_{i}\right)=R_{1_{i}}-R_{2_{i}}
$$

where $K_{\text {diss }}=$ the dissolution rate coefficient $\left(\mathrm{T}^{-1}\right), C_{i}=$ the water phase concentration of component $i, R_{1_{i}}=K_{\mathrm{diss}} C_{\mathrm{eff}_{i}}$, and $R_{2_{i}}=K_{\mathrm{diss}} C_{i}$. Substituting Eq. (6):

$$
R_{1_{i}}=10^{-6} K_{\text {diss }} \frac{C_{\text {pure }_{i}}}{\rho_{\mathrm{o}}} C_{\mathrm{o}_{i}}\left(\frac{1-S_{\mathrm{o}}}{S_{\mathrm{o}}}\right) .
$$

Recall that $C_{\mathrm{o}_{i}}$ is the equivalent immobile oil phase concentration of component $i$ in the BIOMOC simulation. This first-order reaction can be approximated in BIOMOC by using Eq. (1) and assigning $V_{\max }=10^{-6} C_{\text {pure }_{i}} / \rho_{\mathrm{o}}, K=1 / K_{\mathrm{diss}} \gg C_{\mathrm{o}_{i}}$, and $X_{1}=1-S_{\mathrm{o}} / S_{\mathrm{o}}$. The uptake coefficients for the oil phase and dissolved phase of component $i$ are $\beta_{\mathrm{o}_{i}}=1$, $\beta_{\text {dissolved }_{i}}=-1$. Similarly, $R_{2_{i}}$ can be represented in BIOMOC by assigning $V_{\max }=1, K=(1 /$ $\left.K_{\text {diss }}\right) \gg C_{i}, X_{2}=1$ and $\beta_{\mathrm{o}_{i}}=-1, \beta_{\text {dissolve }_{i}}=1$. Outside the oil body zone $X_{1}=X_{2}=0$. Applying this approach to represent the dissolution of the five simulated hydrocarbon components results in ten dissolution reactions.

Five first-order reactions were used to represent anaerobic degradation of BTEX and five first-order reactions were used to represent aerobic degradation of BTEX. These degradation reactions were performed by a microbial population, $X_{3}$, that had a constant biomass concentration of 1.0. Noncompetitive inhibition was used to represent inhibition of anaerobic processes by dissolved oxygen. Stoichiometric relations were used to determine the uptake coefficients for the biodegradation processes. The parameter values for all reactions are listed in Table 1 .

\subsection{UCODE inverse model}

The universal inverse modeling computer code UCODE (Poeter and Hill, 1998) was used to fit the observed concentration history of the Bemidji ground water plume (1072 BTEX and oxygen concentration observations in wells and cores from the period from 1986 to 1997). UCODE uses nonlinear regression for parameter estimation by minimizing a weighted least-squares objective function using a modified Gauss-Newton method.

Available BTEX and oxygen concentration data were used to calibrate the inverse model. Because of the wide range in effective solubilities of BTEX, the concentrations were all normalized by their effective solubility to range between 0 and 1 . Eganhouse et al. (1993a) report that analytical measurement error is fairly uniform and has a coefficient of 
Table 1

Reaction coefficients used in BIOMOC simulations to represent dissolution and biodegradation

\begin{tabular}{|c|c|c|c|c|c|c|c|}
\hline Component & Reaction & Reactants/Products & $\beta$ & $V_{\max }($ per s) & $K$ & $X$ & $k_{\mathrm{s}}$ \\
\hline \multirow[t]{7}{*}{ Benzene } & \multirow[t]{2}{*}{ Dissolution 1} & NAPL benzene & 1 & \multirow[t]{2}{*}{$2.06 \mathrm{e}^{-3}$} & \multirow[t]{2}{*}{$1 / K_{\text {diss }}$} & \multirow[t]{2}{*}{$X_{1}$} & \\
\hline & & Dissolved benzene & -1 & & & & \\
\hline & \multirow[t]{2}{*}{ Dissolution 2} & Dissolved benzene & 1 & \multirow[t]{2}{*}{1} & \multirow[t]{2}{*}{$1 / K_{\text {diss }}$} & \multirow[t]{2}{*}{$X_{2}$} & \\
\hline & & NAPL benzene & -1 & & & & \\
\hline & Anaerobic degradation & Dissolved benzene & 1 & $V_{\operatorname{maxb}} * 1000$ & 1000 & $X_{3}$ & 0.01 \\
\hline & \multirow{2}{*}{ Aerobic degradation } & Dissolved benzene & 1 & \multirow{2}{*}{1.7} & 1000 & $X_{3}$ & \\
\hline & & Dissolved oxygen & 3.07 & & 1000 & & \\
\hline \multirow[t]{7}{*}{ Toluene } & \multirow[t]{2}{*}{ Dissolution 1} & NAPL toluene & 1 & \multirow[t]{2}{*}{$6.26 \mathrm{e}^{-4}$} & \multirow[t]{2}{*}{$1 / K_{\text {diss }}$} & \multirow[t]{2}{*}{$X_{1}$} & \\
\hline & & Dissolved toluene & -1 & & & & \\
\hline & \multirow[t]{2}{*}{ Dissolution 2} & Dissolved toluene & 1 & \multirow[t]{2}{*}{1} & \multirow[t]{2}{*}{$1 / K_{\text {diss }}$} & \multirow[t]{2}{*}{$X_{2}$} & \\
\hline & & NAPL toluene & -1 & & & & \\
\hline & Anaerobic degradation & Dissolved toluene & 1 & $V_{\text {maxt }} * 1000$ & 1000 & $X_{3}$ & 0.01 \\
\hline & \multirow[t]{2}{*}{ Aerobic degradation } & Dissolved toluene & 1 & \multirow[t]{2}{*}{1.7} & 1000 & $X_{3}$ & \\
\hline & & Dissolved oxygen & 3.12 & & 1000 & & \\
\hline \multirow[t]{7}{*}{ Ethylbenzene } & \multirow[t]{2}{*}{ Dissolution 1} & NAPL ethylbenzene & 1 & \multirow[t]{2}{*}{$1.89 \mathrm{e}^{-4}$} & \multirow[t]{2}{*}{$1 / K_{\text {diss }}$} & \multirow[t]{2}{*}{$X_{1}$} & \\
\hline & & Dissolved ethylbenzene & -1 & & & & \\
\hline & Dissolution 2 & Dissolved ethylbenzene & 1 & 1 & $1 / K_{\text {diss }}$ & $X_{2}$ & \\
\hline & & NAPL ethylbenzene & -1 & & & & \\
\hline & Anaerobic degradation & Dissolved ethylbenzene & 1 & $V_{\operatorname{maxe}} * 1000$ & 1000 & $X_{3}$ & 0.01 \\
\hline & Aerobic degradation & Dissolved ethylbenzene & 1 & 1.7 & 1000 & $X_{3}$ & \\
\hline & & Dissolved oxygen & 3.16 & & 1000 & & \\
\hline$m, p$-Xylene & Dissolution 1 & NAPL $m, p$-Xylene & 1 & $1.77 \mathrm{e}^{-4}$ & $1 / K_{\text {diss }}$ & $X_{1}$ & \\
\hline & & Dissolved $m, p$-Xylene & -1 & & & & \\
\hline & Dissolution 2 & Dissolved $m, p$-Xylene & 1 & 1 & $1 / K_{\text {diss }}$ & $X_{2}$ & \\
\hline & & NAPL $m, p$-Xylene & -1 & & & & \\
\hline & Anaerobic degradation & Dissolved $m, p$-Xylene & 1 & $V_{\operatorname{maxm}} * 1000$ & 1000 & $X_{3}$ & 0.01 \\
\hline & Aerobic degradation & Dissolved $m, p$-Xylene & 1 & 1.7 & 1000 & $X_{3}$ & \\
\hline & & Dissolved Oxygen & 3.16 & & 1000 & & \\
\hline$o$-Xylene & Dissolution 1 & NAPL $o$-Xylene & 1 & $2.00 \mathrm{e}^{-4}$ & $1 / K_{\text {diss }}$ & $X_{1}$ & \\
\hline & & Dissolved $o$-Xylene & -1 & & & & \\
\hline & Dissolution 2 & Dissolved $o$-Xylene & 1 & 1 & $1 / K_{\text {diss }}$ & $X_{2}$ & \\
\hline & & NAPL $o$-Xylene & -1 & & & & \\
\hline & Anaerobic degradation & Dissolved $o$-Xylene & 1 & $V_{\operatorname{maxo}} * 1000$ & 1000 & $X_{3}$ & 0.01 \\
\hline & Aerobic degradation & Dissolved $o$-Xylene & 1 & 1.7 & 1000 & $X_{3}$ & \\
\hline & & Dissolved Oxygen & 3.16 & & 1000 & & \\
\hline
\end{tabular}

$\beta=$ uptake coefficient; $V_{\operatorname{maxb}}, V_{\operatorname{maxt}}, V_{\max }, V_{\operatorname{maxm}}, V_{\operatorname{maxo}}=$ asymptotic maximum specific uptake rate of benzene, toluene, ethylbenzene, $m, p$-xylene and $o$-xylene, respectively $(1 / \mathrm{s}) ; K=$ half saturation constant (mg/l); $X=$ microbial population; and, $k_{\mathrm{S}}=$ noncompetitive inhibition constant for inhibition of anaerobic processes by oxygen.

variation of $10 \%$. Attempts to weight the observations using this information were not successful. Observations at points with 0 or very small concentrations had weights that were much too large and dominated the system resulting in unrealistically low simulated concentrations near the oil body. Therefore the concentrations were equally weighted and it was assumed that they all had approximately the same concentration error. All estimated parameters were log transformed and the recommended UCODE control parameter values (Poeter and Hill, 1998) were used. Simulated concentrations were averaged along the 
length of the well screen and compared to observed well concentrations during the inverse procedure.

The parameters estimated during the inverse modeling were: the recharge rate, hydraulic conductivity, dissolution rate coefficient; the first-order anaerobic biodegradation rates for benzene, toluene, ethylbenzene, $m, p$-xylene, and $o$-xylene; and the transverse dispersivity. We initially attempted to estimate all controlling hydrologic and reaction rate parameters, and attempted to use Monod kinetics rather than first-order biodegradation reactions. However, these efforts were not successful because of the high correlation between the two Monod kinetics parameters, the high correlation between longitudinal and transverse dispersivity, and the insensitivity of the inverse solution to longitudinal dispersivity and aerobic degradation. To make the inverse problem well posed, biodegradation reactions were simplified to first-order processes. The plume-scale longitudinal dispersivity was estimated to be $1 \mathrm{~m}$ based on the $0.15-\mathrm{m}$ estimate from the $1.5-\mathrm{m}$ long tracer test. Finally, a fast aerobic biodegradation rate $\left(0.15\right.$ day $\left.^{-1}\right)$ was assumed based on early inverse simulation results and the generally accepted evidence that aerobic degradation of hydrocarbons progresses rapidly in the presence of oxygen.

\section{Regression results for the basic conceptual model}

The criteria generally used to evaluate inverse model results are the following: the estimated parameter values must be reasonable; the model should give a reasonable fit to the data; the residuals should be randomly distributed in space and time; and, the correlation between parameter values must be low.

\subsection{Parameter estimates}

Fig. 3 shows the estimated BTEX anaerobic biodegradation rates and their corresponding $95 \%$ confidence intervals. The estimated field-scale dissolution rate was 0.0066 day $^{-1}$. The estimated anaerobic biodegradation rates for toluene and $o$-xylene $(0.19$ and 0.03 day $^{-1}$ ) were greater than the dissolution rate coefficient. However, the estimated anaerobic biodegradation rates for benzene, ethylbenzene, and $m, p$-xylene $(0.00065$, 0.00071 , and 0.0023 day $^{-1}$ ) were less than the dissolution rate coefficient. The confidence intervals show that there is a large amount of uncertainty in the toluene anaerobic degradation rate. Toluene degrades very rapidly, and was detected in very few observation locations; thus the observations provide less information towards reliably estimating this rate compared to other BTEX degradation rates.

The estimated average annual recharge rate was $0.178 \mathrm{~m} / \mathrm{year}$, a value that falls within the range of independently estimated recharge rates (see Section 1.2). The estimated hydraulic conductivity was $7.02 \times 10^{-5} \mathrm{~m} / \mathrm{s}$, about an order of magnitude higher than the geometric mean conductivity of $5.6 \times 10^{-6} \mathrm{~m} / \mathrm{s}$ obtained from particle-size-distribution estimates (Dillard et al., 1997). This suggests that the plume concentration distribution is a reflection of flow in the high conductivity channels within the heterogeneous porous medium, and/or that conductivities estimated from particle size distributions may underestimate large-scale aquifer hydraulic conductivity. The simulated velocity at the tracer test 


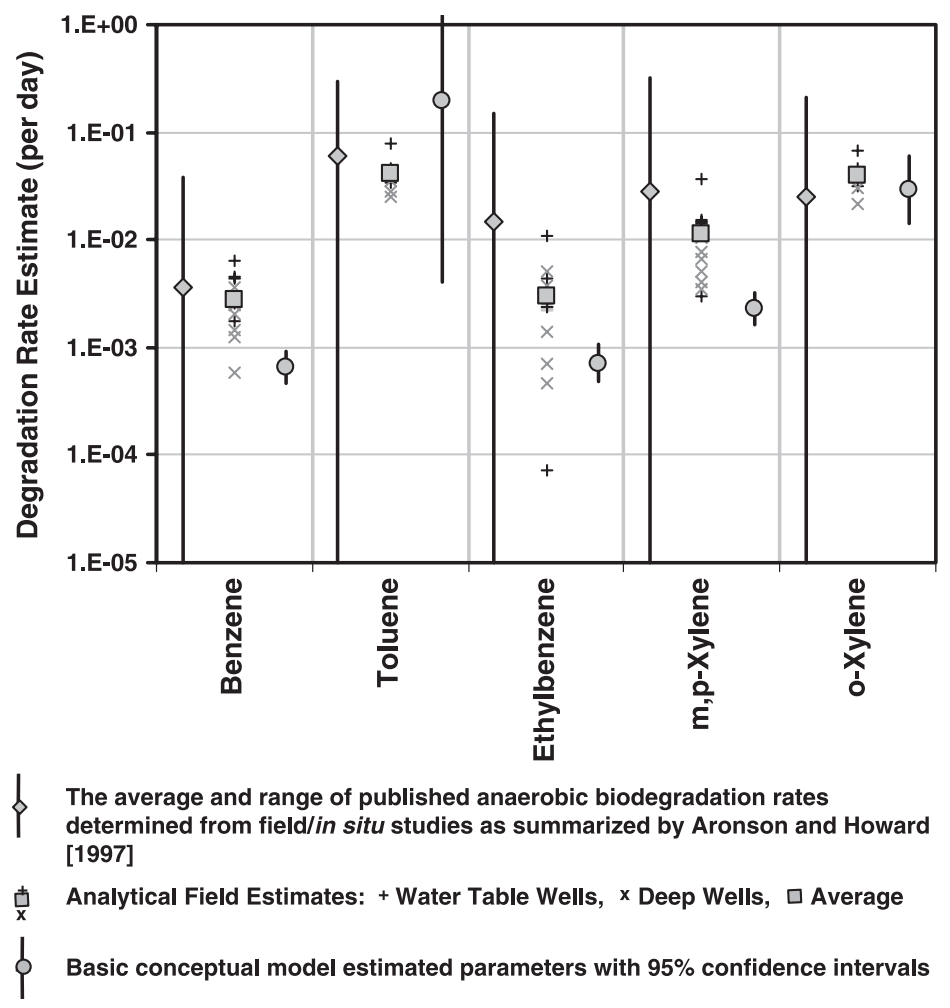

Fig. 3. Published anaerobic biodegradation rates and analytical and regression estimated biodegradation rates for the Bemidji site.

site was $0.053 \mathrm{~m} \mathrm{day}^{-1}$, close to the field estimate of $0.06 \mathrm{~m} \mathrm{day}^{-1}$. The estimated transverse dispersivity was $0.036 \mathrm{~m}$.

\subsection{Comparison of estimated rates to analytical estimates and literature values}

Anaerobic first-order BTEX biodegradation rates were estimated analytically using the approach of Cozzarelli et al. (1990) and Wiedemeier et al. (1996). This method requires the presence of a hydrocarbon tracer that is recalcitrant to anaerobic biodegradation. Attenuation of this tracer is attributed to dispersion, sorption, and volatilization. Attenuation of BTEX in excess of the attenuation of the tracer is assumed to be a result of biodegradation. This method does not take into account the dynamics of hydrocarbon dissolution from the source, aerobic degradation, and nonlinear sorption.

Isopropylbenzene, a hydrocarbon component observed to be relatively recalcitrant to anaerobic degradation at the Bemidji site, was chosen to correct BTEX concentrations for the effects of dispersion, sorption, and volatilization. Isopropylbenzene was more stable than other alkylbenzenes, such as the trimethylbenzene isomers, in the anaerobic zone of the plume but degraded rapidly under aerobic conditions. The corrected BTEX 
concentration (with the effects of dispersion, sorption, and volatilization removed) is given by:

$$
C_{\text {btex }}^{2 \prime}=C_{\text {btex }}^{2} \frac{C_{\text {tracer }}^{1}}{C_{\text {tracer }}^{2}}
$$

where $C_{\text {btex }}^{2,}=$ corrected BTEX concentration at location 2, $C_{\text {btex }}^{2}=$ measured BTEX concentration at location $2, C_{\text {tracer }}^{1}=$ measured isopropylbenzene concentration at location 1 , and $C_{\text {tracer }}^{2}=$ measured isopropylbenzene concentration at location 2 .

This method was applied to estimate anaerobic BTEX biodegradation rates at the water table and at 2-m depth using BTEX concentrations from anaerobic wells for the period from 1986 to 1995. For each year that data were available, first-order anaerobic biodegradation coefficients were estimated using lognormal plots of log corrected concentration versus distance. The tracer test velocity estimate of $0.06 \mathrm{~m}^{\text {day }^{-1}}$ was used to convert the coefficients to biodegradation rates $\left(\right.$ day $\left.^{-1}\right)$. Fig. 3 shows the individual annual first-order biodegradation rate estimates and the average rate for each BTEX compound. Individual biodegradation rate estimates varied from year to year and, in general, were higher at the water table than at the 2-m depth (Fig. 3). This suggests that biodegradation may be occurring more rapidly near the water table due to increased availability of nutrients and/or enhanced availability of substrate or electron donors as a result of water table fluctuations.

Regression-estimated anaerobic degradation rates were compared to the analytically estimated rates and published anaerobic rates determined from field/in situ studies as summarized by Aronson and Howard (1997) (Fig. 3). For benzene, ethylbenzene and $m, p$ xylene the average analytically estimated rates are less than the mean of published rates, and the inverse model rate estimates fall in the lower range of rates obtained analytically. For $o$-xylene the literature, analytical, and regression biodegradation rates are all close to each other. The regression estimate for toluene is larger than the average published and analytical rates, however, these values are within the confidence interval of the regression estimate. The plumes of benzene, ethylbenzene, and $m, p$-xylene extend farther downgradient than toluene and $o$-xylene (Fig. 4). It is possible that the analytically estimated rates for benzene, ethylbenzene, and $m, p$-xylene are influenced by aerobic degradation, even though only anaerobic wells were used. Some aerobic degradation may be occurring on the edges of the anaerobic plume due to dispersion of small amounts of oxygen into the anaerobic region resulting in higher apparent anaerobic biodegradation rates. Another possible explanation for the higher analytically determined rates is that the true biodegradation rates are not uniform in the field, because of sequential biodegradation processes, and the analytical values are representative of terminal electron processes having higher biodegradation rates, whereas the model estimates are an average rate for all processes.

Dissolution coefficients have been measured in the laboratory at velocities that are several orders of magnitude higher than the Bemidji field velocity of $0.06 \mathrm{~m}$ day $^{-1}$ (Powers et al., 1994). No measurements have been made in the low velocity range. Dillard et al. (2001) used a pore network model to evaluate dissolution coefficients over a large range of velocities and oil saturations. Using the average velocity $\left(v_{\mathrm{w}}\right)$, the median grain 

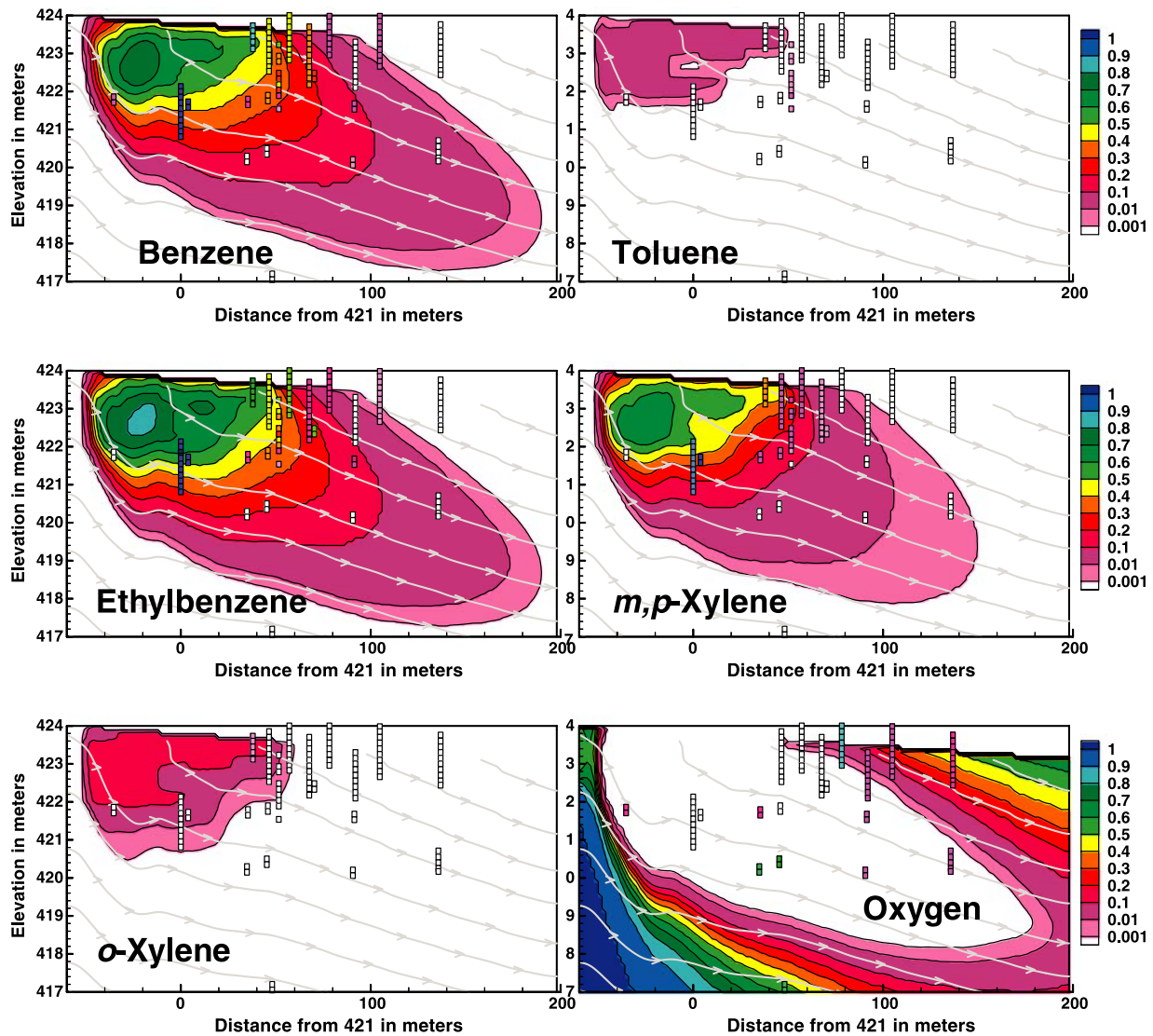

Fig. 4. The 1993 distribution of normalized observed and simulated BTEX and oxygen concentrations. Colored contours represent simulated concentrations and colored boxes represent observed well and core concentrations. Well concentrations are plotted along the entire length of the well screen.

size $\left(d_{50}\right)$ and the molecular diffusion coefficient for benzene $\left(D_{\mathrm{m}}\right)$, the modified Peclet number $\left(P e^{\prime}\right)$ of Dillard et al. (2001) at the Bemidji site is approximately:

$$
P e^{\prime}=\frac{v_{\mathrm{w}} d_{50}}{D_{\mathrm{m}}}=\frac{\left(6.9 \times 10^{-7} \mathrm{~m} / \mathrm{s}\right) 0.00025 \mathrm{~m}}{1.1 \times 10^{-9} \mathrm{~m}^{2} / \mathrm{s}}=0.16
$$

Dillard et al. (2001) predicted dissolution coefficients in the range of $0.1-1$ day $^{-1}$ at this Peclet number depending on saturation, and wetting and drying history. This value is significantly higher than the model estimated value of 0.0066 day $^{-1}$. It is not surprising that the field-scale value is significantly different than the pore-scale value because dissolution is a complex process that depends on velocity, saturation, wetting history, particle-size-distribution, and heterogeneity. Recall that the water velocities within the oil body are reduced relative to the average aquifer flow rate by one to two orders of magnitude because of the reduction in water relative permeability. Thus, most of the water flowing through the oil body actually has a Peclet number one to two orders of magnitude 
less than 0.16 . Also, because of the reduced water relative permeability in the oil zone, there is significant deflection of water flow around the oil body resulting in less water-oil interaction. The model of Dillard et al. (2001) did not extend to this low velocity range and, also, did not incorporate large-scale, multi-dimensional bypassing effects.

\subsection{Model fit, parameter correlations, and parameter sensitivity}

The correlation coefficient for the inverse model fit was 0.71 and the standard error of regression was 0.22 . These values reflect the difficulty of fitting a real data set that represents the interaction of complex processes and includes significant spatial and temporal variability. The distribution of observed and simulated concentrations is shown in Fig. 4. The contours represent simulated 1993 concentrations and the points represent observed 1993 well and core concentrations. Well concentrations are plotted along the entire length of the well screen. The calibrated simulation reproduced the general largescale behavior of the plume, but did not reproduce the observed small-scale spatial and temporal variability in concentrations. Observed data in Fig. 4 show significant variation in concentrations over short horizontal and vertical distances that are probably due to spatial variability in hydraulic properties and small-scale variations in the distribution of the oil body that were not captured during the interpolation between measured oil saturations. The main discrepancies between the observed and simulated plumes are that the very high observed concentrations below the oil body at $x=0$ are not reproduced, and that the simulated oxygen concentrations on the edges of the plume are underpredicted with a corresponding overprediction of benzene, ethylbenzene, and $m, p$-xylene concentrations. This could be due to neglecting dispersion of oxygen in the direction perpendicular to the transect; neglecting physical and biogeochemical heterogeneity; and/or neglecting seasonal effects. Oxygen concentrations on the edges of the plume varied from year to year and were relatively high in 1993.

Fig. 5 shows a plot of residuals versus normalized simulated concentrations and the zone bracketed by \pm the standard error of the regression. Ideally, the residuals should be randomly distributed about zero and $95 \%$ should fall within \pm the standard error of the regression. However, there are quite a few large residuals mainly for locations where the normalized observed concentration was greater than one. Normalized observed concentrations in some wells and cores near the oil body were greater than one indicating the observed concentrations were greater than the assumed effective solubilities. It is possible that the oil equilibration tests underestimated solubilities. At locations where the observed concentration was zero the residuals are equal to the negative of the simulated value and fall along a line with a slope of negative one.

Correlations between parameters were all less than 0.74 . The highest correlations were between dissolution rate and anaerobic biodegradation rates because of the interdependence of these two processes. However, the correlations were not so high as to cause problems with the inverse procedure. This was not true for inverse models that used individual dissolution rates for each BTEX component. Two different inverse models were attempted. First, individual dissolution and biodegradation rates were fit for each BTEX component. In this model the only coupling between the BTEX components was through the simultaneous use of oxygen during aerobic biodegradation. It was not possible to 


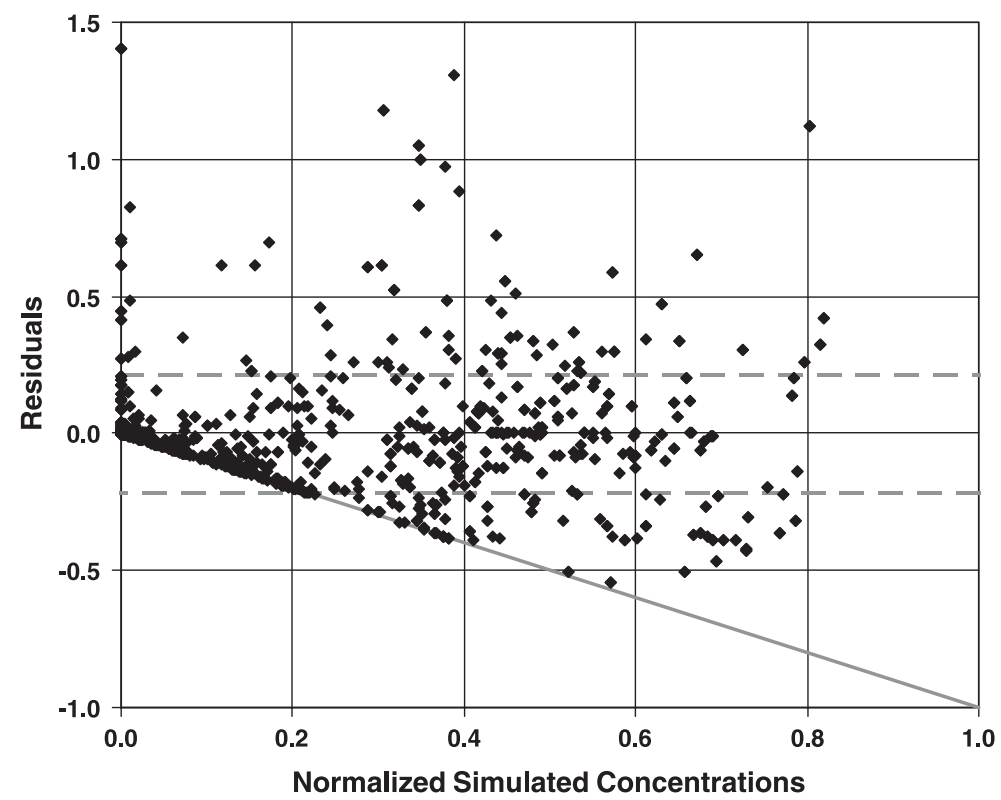

Fig. 5. Plot of residuals versus normalized simulated concentrations and the zone bracketed by \pm the standard error of the regression (dashed line).

obtain reliable estimates of toluene and $o$-xylene dissolution and anaerobic biodegradation rates because the absolute value of the correlation between the parameters became greater than 0.95 . Individual dissolution rates obtained for benzene, ethylbenzene, and $m, p$-xylene were $4.2 \times 10^{-3}, 5.5 \times 10^{-3}$, and $4.9 \times 10^{-3}$ day $^{-1}$, respectively, suggesting that the use of a single dissolution rate coefficient is a reasonable assumption. A second model that fit individual dissolution rates and biodegradation rates for each BTEX component (no coupling between components) could not obtain a unique solution for any of the rates because of the high parameter correlation for all components. A well-posed inverse problem could only be obtained with the assumption of a single dissolution rate and coupled use of oxygen for aerobic degradation.

Fig. 6 shows the composite scaled sensitivities for the estimated and fixed parameters. The composite scaled sensitivity is a measure of the information content of the observations for the estimation of a parameter and consequently represents the sensitivity of the simulated equivalent of the observation to the parameter (Poeter and Hill, 1998). The solution is most sensitive to the recharge rate and hydraulic conductivity. Together, these two parameters control the orientation of flow paths in the system. The estimated parameter with the next highest composite scaled sensitivity was the dissolution rate, followed by the benzene, ethylbenzene, $m, p$-xylene, $o$-xylene, and toluene anaerobic degradation rates, respectively. The dissolution coefficient controls the mass flux of each component entering the ground water plume. The anaerobic degradation rates control the amount of mass that remains in the plume. The solution is more sensitive to benzene, ethylbenzene, and $m, p$-xylene anaerobic degradation rates than the toluene and $o$-xylene 


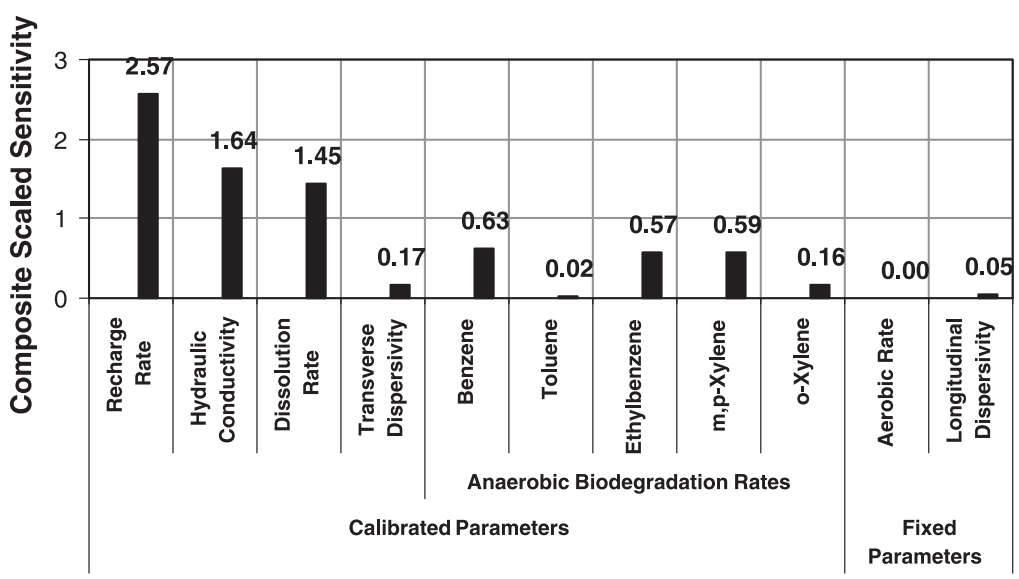

Fig. 6. Composite scaled sensitivity of estimated and fixed parameters for the basic simulation.

rates because the plumes of these components are larger than the toluene and $o$-xylene plumes and they have more nonzero concentration observations. The solution is moderately sensitive to transverse dispersivity. The solution showed little sensitivity to the fixed aerobic degradation rate or the longitudinal dispersivity. Aerobic degradation occurs very rapidly and therefore the solution is not sensitive to the rate as long as it is fast enough. Concentration observations were generally made after the plume had reached a stage where it was not advancing or changing rapidly and, therefore, not influenced by the value of longitudinal dispersivity. This was confirmed by comparing simulation results obtained with different longitudinal dispersivities.

\subsection{Oil body and ground-water plume evolution}

The simulation results were used to examine the amount of BTEX removed from the oil body, the distribution of BTEX in the ground water plume, and the amount of BTEX removed by aerobic and anaerobic degradation processes. Fig. 7 shows the oil saturation contours and percent hydrocarbon remaining in the oil body at the end of the simulation period (18 years of dissolution) for benzene, toluene, and ethylbenzene. The greatest degree of dissolution occurred on the low saturation outer edges of the oil body. The high oil saturation, low water flux core of the oil body changed relatively little, whereas the edges of the oil body that interacted with faster flowing water were significantly depleted in BTEX. The simulation predicts that $5.3 \%$ of the initial BTEX mass present in the oil body was dissolved from the oil. The amount of removal from the oil body varied from component to component and was $10.2 \%, 8.6 \%, 1.2 \%, 1.4 \%$, and $2.7 \%$ for benzene, toluene, ethylbenzene, $m, p$-xylene, and $o$-xylene, respectively. In the absence of biodegradation individual component removal would be proportional to effective solubility. However, biodegradation reduces the dissolved concentration of the component, increasing the driving force for dissolution (Eq. (7)) and enhancing removal from the oil body. For example toluene has an effective solubility less than half that of benzene, however, its 

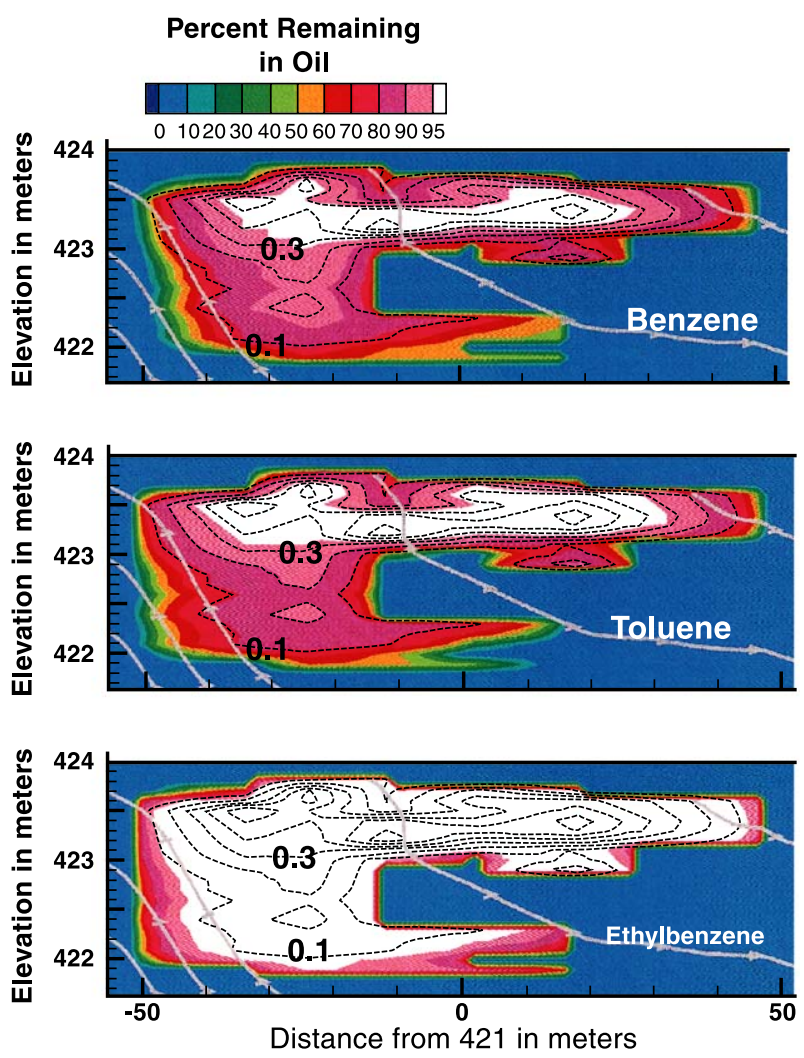

Fig. 7. Plots showing the percent hydrocarbon remaining in the oil body at the end of the simulation period (18 years of dissolution) and oil saturation contours.

removal rate from the oil body is roughly $85 \%$ that of benzene because of its relatively high anaerobic biodegradation (Fig. 7). Very little ethylbenzene has been removed from the oil body because of its low effective solubility and anaerobic degradation rate. Simulation results illustrate that BTEX dissolution from the oil body is proportional to effective solubility and is enhanced by anaerobic degradation.

The simulated BTEX plumes shown in Fig. 4 illustrate that the extent of the dissolved plume of each BTEX component is controlled by its anaerobic biodegradation rate. Aerobic degradation only affects the outer edges of the BTEX plume. Fig. 8 shows the fraction of each dissolved hydrocarbon removed by anaerobic and aerobic degradation from 1979 to 1997 . The proportion of anaerobic degradation is directly proportional to the anaerobic degradation rate. The proportion of aerobic degradation is inversely proportional to the anaerobic degradation rate. When less anaerobic degradation of a component occurs, its plume extends farther downgradient and comes in greater contact with oxygen resulting in increased aerobic degradation. For example, toluene degraded very rapidly anaerobically and, therefore, did not extend downgradient from the oil body and did not undergo anaerobic degradation. Ethylbenzene degraded very slowly anaerobically and its plume 


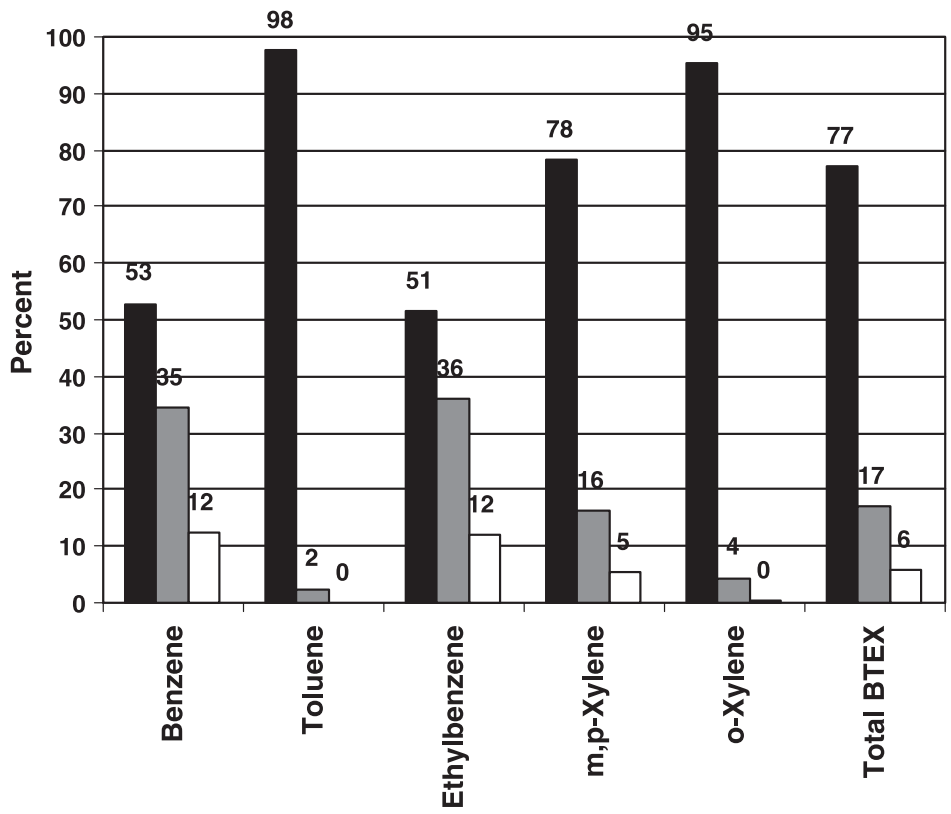

Degraded Anaerobically $\square$ Degraded Aerobically $\square$ Undegraded

Fig. 8. Simulated percent of BTEX dissolved from oil body removed by degradation, and remaining in the ground-water plume, after 18 years.

extended downgradient where it mixed with oxygenated water and degraded aerobically. Overall, $77 \%$ of BTEX dissolved from the oil body was removed by anaerobic degradation and $17 \%$ was removed by aerobic degradation. Only $6 \%$ remained in the ground-water plume. Anaerobic processes can be very effective at controlling plume migration and must be well understood to predict plume evolution.

The simulation showed that the consumption of oxygen depended on the effective solubility and anaerobic biodegradation rate of each BTEX compound. For example, benzene had the highest effective solubility and a relatively small anaerobic biodegradation rate resulting in it being most of the BTEX mass in the plume. Aerobic degradation of benzene consumed $80 \%$ of the available oxygen.

\section{Regression results for alternative conceptual models}

Fig. 9 shows the observed and simulated concentrations at a water table well $46 \mathrm{~m}$ downgradient from well 421 and illustrates the range of temporal variability in observed concentrations. In addition to the fluctuations in concentration from year to year, benzene, ethylbenzene and $m, p$-xylene display a trend of increasing concentration with time. The basic conceptual model does not reproduce the annual fluctuations, or the trends in concentration. This suggests that additional processes influence the plume. Several 

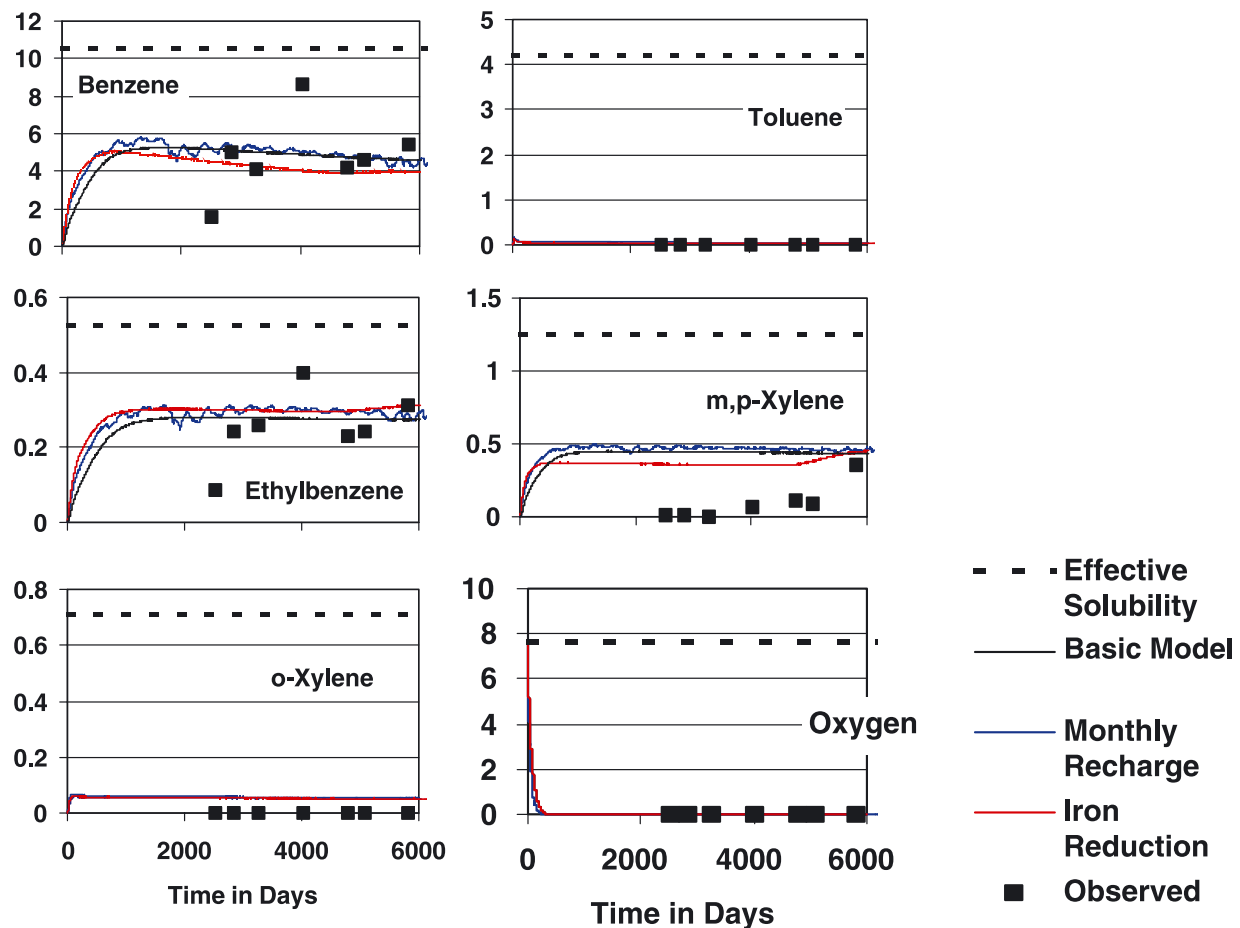

Fig. 9. Plot of observed and simulated BTEX concentrations at a water table well $46 \mathrm{~m}$ downgradient from Well 421 for the basic, monthly recharge, and iron reduction conceptual models.

conceptual models were tested to determine if the data would allow discrimination between conceptual models of varying complexity, and if the observed variability could be reproduced. A summary of the conditions and results of each conceptual model and its variation from the basic simulation follows.

\subsection{Field estimated rates}

This case used the same conceptual model as the basic simulation, however, the anaerobic biodegradation rates were fixed at the average analytically estimated values (Fig. 3). Only two parameters, the dissolution coefficient and transverse dispersivity, were estimated in the inverse model. This approach is appealing because it includes biodegradation processes and is much less demanding computationally. A relatively good fit (correlation coefficient $=0.67$ ) was obtained by using the average analytically estimated field biodegradation rates however, the rates used were an average of many years of estimates (see Fig. 3) and there was significant variability in estimated values from year to year. Although this approach is computationally advantageous, using data from a single year of sampling could introduce significant error into parameter estimates and model predictions of plume behavior. The estimated dissolution coefficient for this conceptual model was larger than for the basic simulation (Fig. 10) because the analytically 

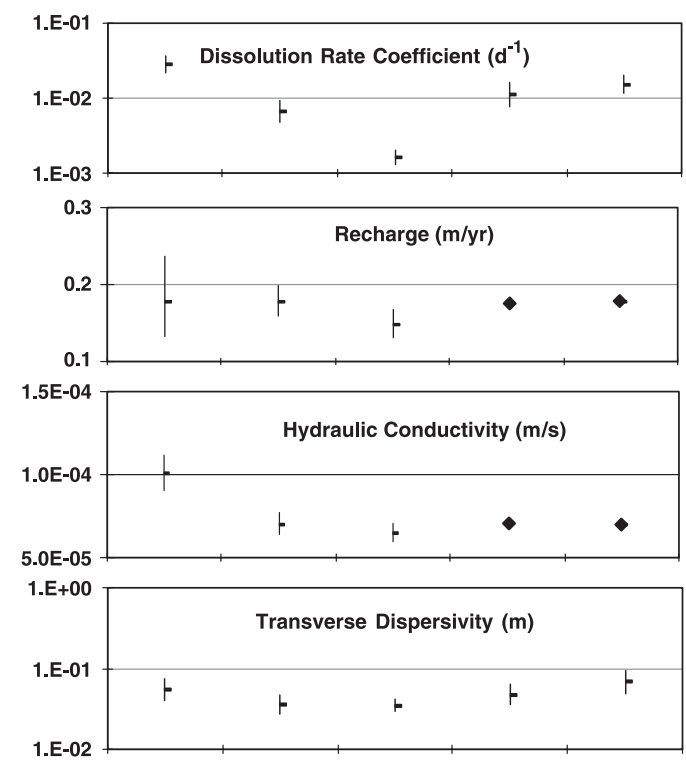

- Parameter fixed at this value in the regression model
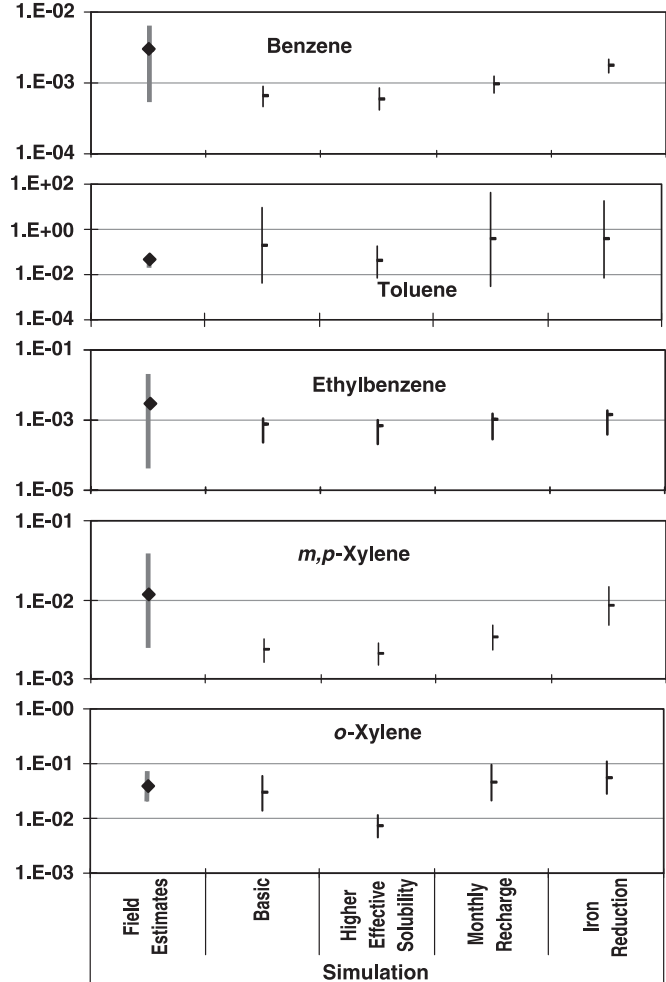

Fig. 10. The estimated parameters and $95 \%$ confidence intervals for each simulated conceptual model. 
determined field biodegradation rate estimates were higher than the basic simulation rate estimates.

\subsection{Higher effective solubility}

Observations of benzene, ethylbenzene, and $m, p$-xylene concentrations at some locations in the field were significantly higher than the effective solubilities predicted using the equilibrium data of Eganhouse et al. (1996). This suggests that the equilibrium experiments may have underestimated effective solubilities because the oil samples had already undergone significant alteration in the field. A simulation was carried out using the highest observed concentrations of benzene $(18.0 \mathrm{mg} / \mathrm{l})$, ethylbenzene $(1.0 \mathrm{mg} / \mathrm{l})$, and $m, p$-xylene $(2.84 \mathrm{mg} / \mathrm{l})$ for effective solubility. The inverse fit was not better (correlation coefficient $=0.68$ ). The inverse solution resulted in lower dissolution rate coefficient (Fig. 10).

\subsection{Monthly recharge}

The basic conceptual model was modified to include temporally variable recharge and the hydraulic conductivity was fixed at the value obtained in the basic simulation. Monthly recharge estimates were obtained by scaling monthly precipitation during each year by the ratio of the annual recharge for that year, estimated from well hydrographs, to the average annual precipitation for the period from 1984 to 1999 (Fig. 11). Recharge was taken to be 0 during the winter months (December through February) and precipitation that accumu-

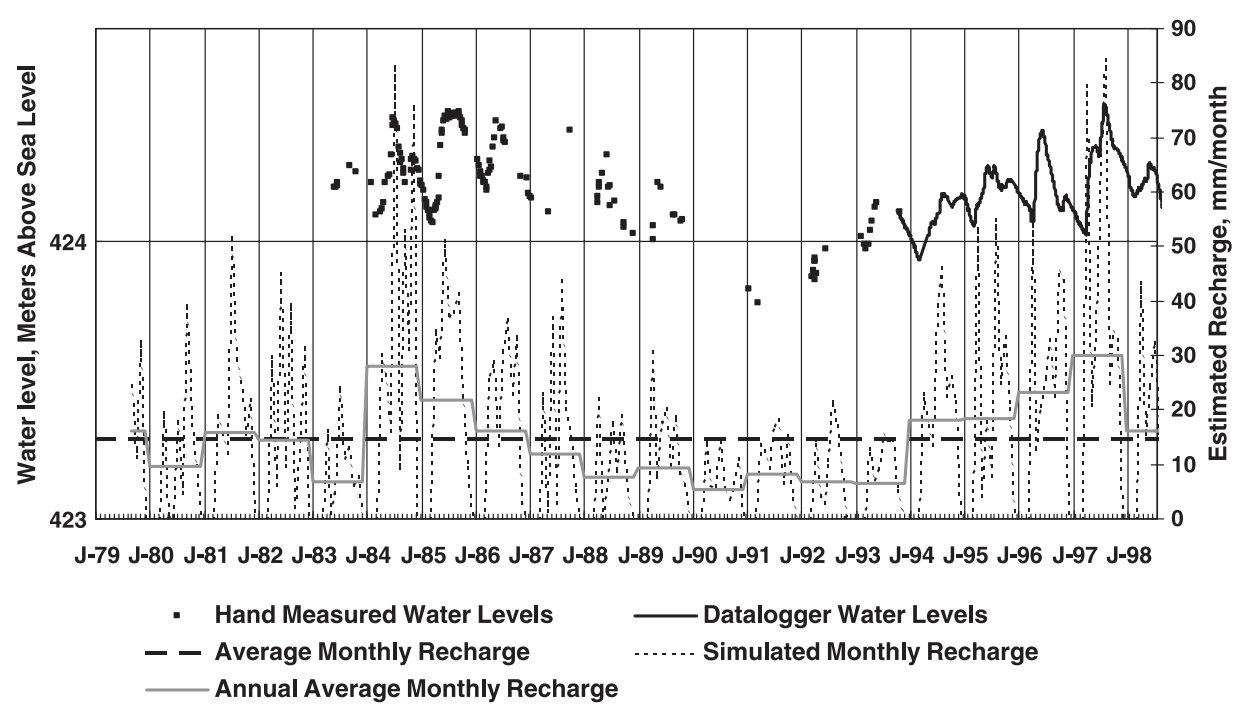

Fig. 11. Observed water levels, average monthly recharge (1979-1998) used in the basic simulation, average annual monthly recharge, and simulated monthly recharge used in the monthly recharge conceptual model simulation. 
lated during this period was added to March recharge to represent snowmelt. Recharge was lagged one month after precipitation occurred based on comparison of precipitation records and water level records. The flow field was modeled as a succession of steady states. Comparison to a simulation with full transient flow showed that this simplification was acceptable.

The introduction of monthly recharge changed the fit slightly (correlation coefficient $=0.69$ ) but fell short of reproducing the observed temporal variability in concentrations at the water table (Fig. 9). The effect of variable recharge was most pronounced at observation locations on the edge of the plume due to the subtle upward and downward movement of the plume in response to changes in recharge rates (Fig. 12). This simulation suggests that the wide range of concentration variability observed near the water table cannot be fully explained by changes in flow patterns or dilution effects caused by variable recharge. Variable recharge and the fluctuating water table probably result in variability in biodegradation processes due to changes in redox conditions (Vroblesky and Chapelle, 1994), substrate and electron donor availability, and nutrient infiltration. Including this variability was beyond the scope of the work presented here.
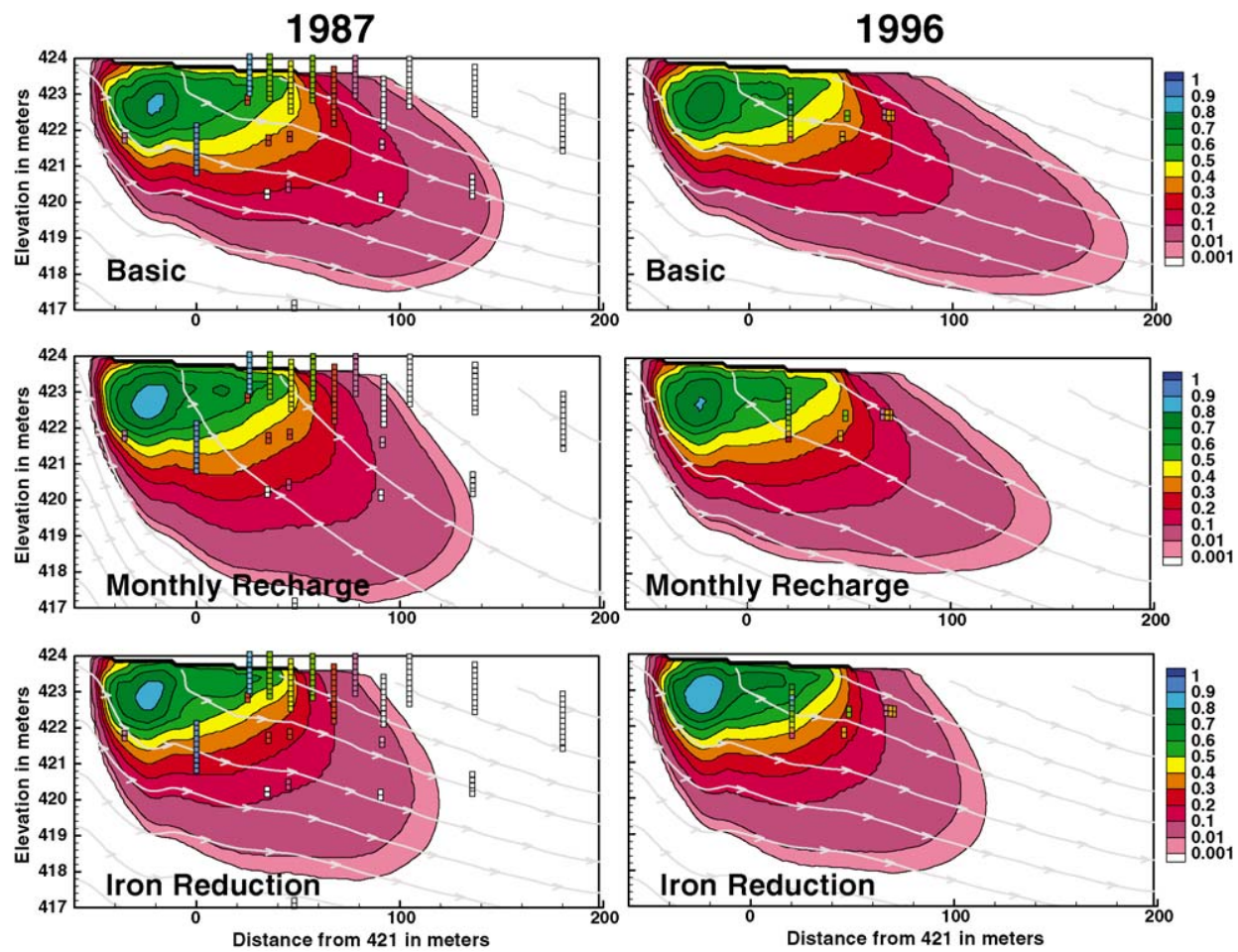

Fig. 12. 1987 and 1996 observed (colored boxes) and simulated (colored contours) benzene concentrations for the basic, monthly recharge, and iron reduction conceptual models. 


\subsection{Iron reduction}

Field evidence (Cozzarelli et al., 2001; Bekins et al., 2001) suggests that the benzene plume is expanding with time as the ground-water plume evolves from iron reducing to methanogenic conditions. Concentration trends observed in Fig. 9 also suggest that benzene, ethylbenzene, and $m, p$-xylene concentrations are increasing with time. However, the basic simulation predicted decreasing benzene concentrations and level ethylbenzene and $m, p$-xylene concentrations. In this conceptual model it was assumed that benzene, ethylbenzene, and $m, p$-xylene degrade anaerobically by iron reduction, that degradation continues only as long as solid phase iron is available (Table 2), and that methanogenic degradation of these compounds is negligible. The measured background solid phase iron concentration of $1500 \mathrm{mg} / \mathrm{l}$ of bulk aquifer volume $(17 \mathrm{mmol} / \mathrm{kg}$ sediment) (Lovley et al., 1989) was used as the initial condition. All other reactions remained the same as in the basic simulation. Recharge and hydraulic conductivity were fixed at the values obtained from the basic simulation. The seven estimated parameters were the dissolution coefficient, the iron reduction rate for benzene, ethylbenzene, and $m, p$-xylene, the anaerobic degradation rate of toluene and $o$-xylene, and the transverse dispersivity.

The correlation coefficient for the iron reduction simulation was 0.70 , very close to that of the basic simulation (0.71). This conceptual model begins to capture the trends of increasing benzene, ethylbenzene, and $m, p$-xylene concentrations observed in the data (Fig. 9). The benzene, ethylbenzene, and $m, p$-xylene anaerobic degradation rates representing iron reduction are higher than in other conceptual models and approach the analytical field estimates (Fig. 10).

Fig. 12 contrasts the plume evolution in the basic and iron reduction simulations. Concentrations in the core of the plume of the basic simulation decrease with time, whereas the edge of the plume migrates down gradient. However, in the iron reduction simulation, the edge of the plume is relatively stable and the core of the plume is expanding with time.

Other conceptual models were considered that included the effects of contaminated recharge, heterogeneity, larger BTEX effective solubilities, zero-order biodegradation rates, oil inhibition of biodegradation, and dissolution rate as a function of oil saturation.

Table 2

Reaction coefficients used in BIOMOC simulations to represent iron reduction biodegradation

\begin{tabular}{|c|c|c|c|c|c|c|c|}
\hline Component & Reaction & Reactants/Products & $\beta$ & $V_{\max }$ & $K$ & $X$ & $k_{\mathrm{s}}$ \\
\hline \multirow[t]{2}{*}{ Benzene } & $\begin{array}{l}\text { Anaerobic } \\
\text { degradation }\end{array}$ & Dissolved benzene & 1 & $V_{\operatorname{maxb}} * 1000$ & 1000 & $X_{3}$ & 0.01 \\
\hline & & Solid phase iron & 21.5 & & 10 & & \\
\hline \multirow[t]{2}{*}{ Ethylbenzene } & $\begin{array}{l}\text { Anaerobic } \\
\text { degradation }\end{array}$ & Dissolved ethylbenzene & 1 & $V_{\operatorname{maxe}} * 1000$ & 1000 & $X_{3}$ & 0.01 \\
\hline & & Solid phase iron & 21.0 & & 10 & & \\
\hline \multirow[t]{2}{*}{$m, p$-Xylene } & $\begin{array}{l}\text { Anaerobic } \\
\text { degradation }\end{array}$ & Dissolved $m, p$-Xylene & 1 & $V_{\operatorname{maxm}} * 1000$ & 1000 & $X_{3}$ & 0.01 \\
\hline & & Solid phase iron & 21.0 & & 10 & & \\
\hline
\end{tabular}

$\beta=$ uptake coefficient; $V_{\operatorname{maxb}}, V_{\max }, V_{\max }, V_{\operatorname{maxm}}, V_{\max }=$ asymptotic maximum specific uptake rate of benzene, toluene, ethylbenzene, $m, p$-xylene and $o$-xylene, respectively $(1 / \mathrm{s}) ; K=$ half saturation constant $(\mathrm{mg} / \mathrm{l}) ; X=$ microbial population; and, $k_{\mathrm{s}}=$ noncompetitive inhibition constant for inhibition of anaerobic processes by oxygen. 
Including these factors made little improvement in the goodness-of-fit. The simulations fit the observed data almost equally well by representing biodegradation with first-order or zero-order degradation rates. This suggests that the dissolved BTEX concentration data are insufficient to discriminate between these conceptual models.

\subsection{Fifty-year predictions with alternative conceptual models}

The predicted benzene plume 50 years after the spill is shown in Fig. 13 for three different conceptual models: (1) the basic simulation, (2) the two-parameter simulation with rates fixed at the analytically estimated field values, and (3) the iron reduction simulation. The predicted plume was similar for the basic simulation and the two-
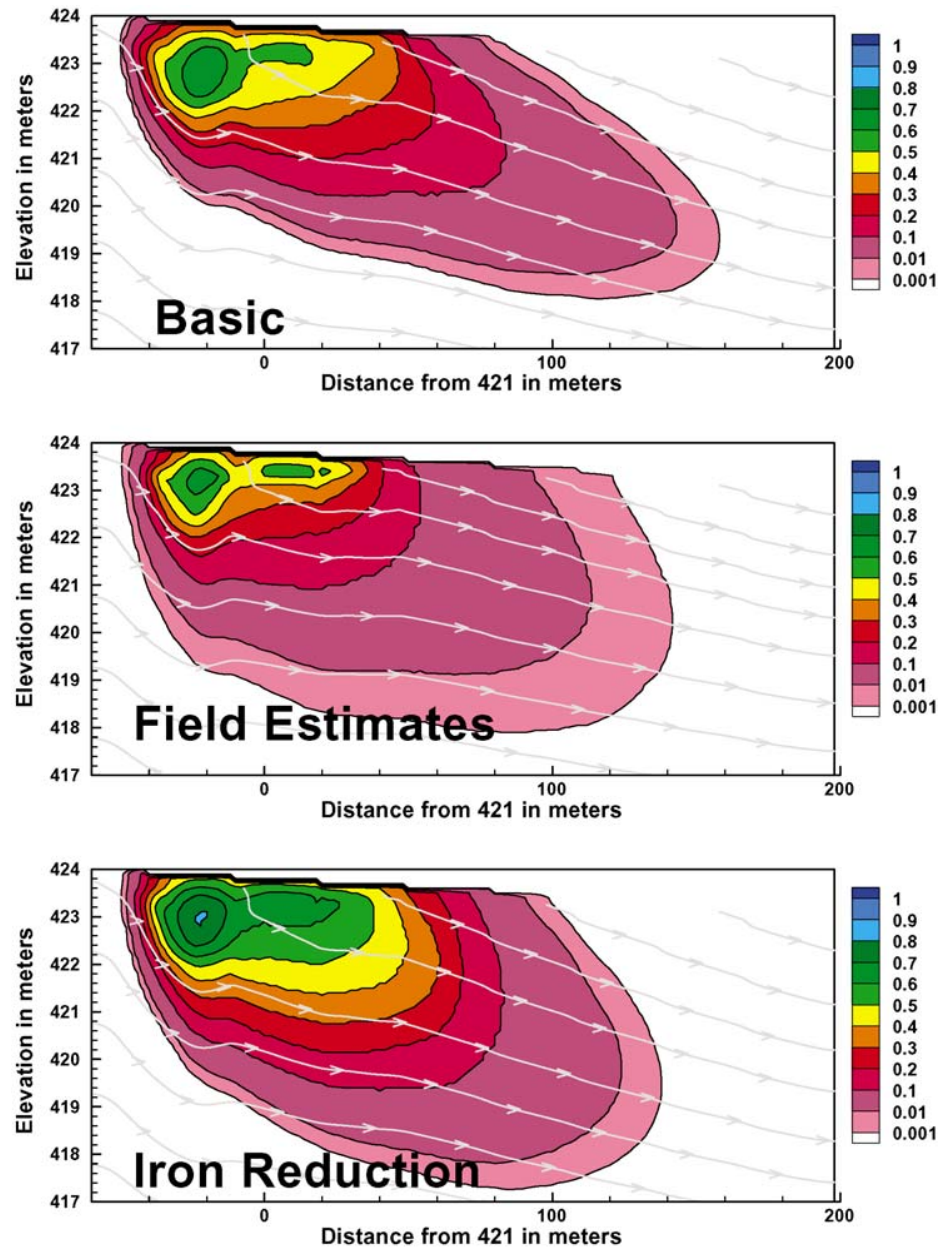

Fig. 13. Predicted 50-year normalized benzene plume for the basic, field estimates, and iron reduction conceptual model simulations. 
parameter simulation made using analytical field estimates of anaerobic degradation rates. However, $77 \%$ of the benzene remained in the oil body for the basic simulation and only $67 \%$ remained for the field estimate case. Predictions of the time frame for natural attenuation of all benzene in the oil body would differ significantly for these two cases. The mass of BTEX in the oil body is very large compared to that in the dissolved groundwater plume. Hence, small differences in dissolution and biodegradation rates translate to large differences in contamination lifespan.

The iron reduction model predicted a significantly different benzene plume with $73 \%$ of the benzene remaining in the oil body. The iron reduction benzene plume did not extend as far downgradient as the basic and field estimates plumes, and the concentrations within the core of the iron reduction plume were significantly higher. This model predicts that the benzene plume will expand with time as iron is depleted, whereas, the basic simulation model predicts a contracting benzene plume.

\section{Discussion and conclusions}

Inverse modeling of BTEX dissolution, transport, and biodegradation at the Bemidji, $\mathrm{MN}$, oil spill site using simplified representations of biodegradation and dissolution processes reproduced general plume behavior, but did not reproduce the observed smallscale spatial and temporal variability in concentrations. However, the model was useful for estimating bulk field-scale biodegradation and dissolution rate parameters, and for examining BTEX fate in the subsurface.

\subsection{Effectiveness of inverse modeling and ability to evaluate alternative conceptual models}

The criteria generally used to evaluate inverse model results are: the estimated parameter values must be reasonable; the model should give a reasonable fit to the data; the residuals should be randomly distributed in space and time; and, the correlation between parameter values must be low (Hill, 1998). These criteria were satisfied only when: coupled transport and degradation processes were incorporated into the model; a single dissolution rate coefficient was used for all BTEX components; biodegradation reactions were simplified to first-order processes; the longitudinal dispersivity was fixed; and, a fast aerobic biodegradation rate was assumed.

The parameters successfully estimated during the inverse modeling were: recharge rate, hydraulic conductivity, dissolution rate coefficient; first-order BTEX anaerobic biodegradation rates; and transverse dispersivity. We fit the observed plume using several alternative conceptual models of the hydrologic system and biodegradation processes. Goodness-of-fit measures and estimated parameter values were similar for the different models. The correlation coefficients for these fits ranged from 0.67 to 0.71 .

The similar fits obtained with the different conceptual models reflect the fact that the ground-water BTEX concentration data alone are not adequate to discriminate between different process models. The mass of BTEX in the ground water plume is similar for all conceptual model simulations. The dissolution rate coefficient and the biodegradation rates 
in each conceptual model resulted in the same plume mass. The general character of the observed BTEX plume has not changed significantly during the period of record, and subtle changes are masked by small-scale spatial and temporal variability in observed concentrations. Information on BTEX removal from the oil body and concentration histories of biodegradation products could help evaluate which model is most appropriate.

Although goodness-of-fit measures for the different conceptual models were not significantly different, long-term predictions made with the models were quite variable. This has significant implications for assessing the long-term efficacy of natural attenuation at a site. The use of an incorrect conceptual model could lead to erroneous conclusions regarding long-term plume migration control.

\subsection{Field-scale dissolution and anaerobic biodegradation rates estimates}

Although it was difficult to discriminate between the alternative conceptual models, the results for all models were quite similar. Estimated individual BTEX biodegradation rates were within an order of magnitude or less for the different conceptual models. In general, toluene and $o$-xylene degradation rates were greater than the dissolution coefficient. Benzene, ethylbenzene, and $m, p$-xylene rates were less than the dissolution coefficient. The geometric mean of anaerobic biodegradation estimates obtained from the five alternative conceptual models are: benzene, 0.0011 day $^{-1}$; toluene, 0.13 day $^{-1}$; ethylbenzene, $0.0011 \mathrm{day}^{-1}$; $m, p$-xylene, $0.0043 \mathrm{day}^{-1}$; and $o$-xylene, $0.029 \mathrm{day}^{-1}$. Benzene, ethylbenzene, and $m, p$-xylene regression estimated degradation rates tend to fall in the lower range of analytically estimated rates, except for the iron reduction conceptual model estimates, which are close to the average analytical estimates. The geometric mean estimated field-scale dissolution rate was 0.0088 day $^{-1}$, which is less than predicted by pore-scale models.

\subsection{BTEX dissolution, biodegradation, and influence of biodegradation on dissolution}

The basic simulation calibrated model was used to determine the BTEX mass balance in the oil body and ground-water plume. The percent BTEX mass removed from the oil body after 18 years was: benzene, $10.2 \%$; toluene, $8.6 \%$; ethylbenzene, $1.2 \% ; m, p$-xylene, $1.4 \%$; and, $o$-xylene, $2.7 \%$. Dissolution from the oil body was greatest for compounds with large effective solubilities (benzene) and with large degradation rates (toluene and $o$ xylene). The outer low oil saturation edges of the oil body become depleted of BTEX more quickly than the high oil saturation core. Comparison of a model fit that neglected biodegradation processes with the basic model showed that biodegradation enhanced dissolution by $260 \%$ for benzene, $850 \%$ for toluene, $320 \%$ for ethylbenzene, $430 \%$ for $m, p$-xylene, and $810 \%$ for $o$-xylene. Biodegradation lowered BTEX concentrations in the water phase resulting in a stronger driving force for dissolution. Anaerobic degradation removed $77 \%$ of the BTEX that dissolved in the water phase and aerobic degradation removed $17 \%$.

The amount of BTEX removed from the oil body varied significantly for the different conceptual models. As expected, conceptual models with greater biodegradation resulted in greater removal of BTEX from the oil body. 


\section{Acknowledgements}

This research was funded by the U.S. Geological Survey's Toxic Substances Hydrology Program. We would like to thank Claire Tiedeman, Jim Constantz, Allen Moench, John Molson, and two anonymous reviewers for their valuable comments and suggestions that contributed significantly to the improvement of this paper.

\section{References}

Aronson, D., Howard, P.H., 1997. Anaerobic biodegradation of organic chemicals in groundwater: a summary of field and laboratory studies. Syracuse Research Corporation (SRC TR-97-0223F, 110 pp.).

Baedecker, M.J., Cozzarelli, I.M., Siegel, D.I., Bennett, P.C., Eganhouse, R.P., 1993. Crude oil in a shallow sand and gravel aquifer: 3. Biogeochemical reactions and mass balance modeling in anoxic ground water. Appl. Geochem. 8, 569-586.

Bekins, B.A., Cozzarelli, I.M., Godsy, E.M., Warren, E., Essaid, H.I., Tuccillo, M.E., 2001. Progression of natural attenuation processes at a crude oil spill site: II. Controls on spatial distribution of microbial populations. J. Contam. Hydrol. 53, 387-406.

Bennett, P.C., Siegel, D.I., Baedecker, M.J., Hult, M.F., 1993. Crude oil in a shallow sand and gravel aquifer: 1. Hydrogeology and inorganic geochemistry. Appl. Geochem. 8, 529-549.

Borden, R.C., Bedient, P.B., Lee, M.D., Ward, C.H., Wilson, J.T., 1986. Transport of dissolved hydrocarbons influenced by oxygen-limited biodegradation: 2. Field application. Water Resour. Res. 22 (13), 1983-1990.

Burris, D.R., MacIntyre, W.G., 1986. Solution of hydrocarbons in a hydrocarbon-water system with changing phase composition due to evaporation. Environ. Sci. Technol. 20, 296-299.

Chaplin, B.P., Delin, G.N., Baker, R.J., Lahvis, M.K., 2002. Long-term evolution of biodegradation and volatilization rates in a crude oil-contaminated aquifer. Bioremediat. J. 6 (3), 237-255.

Chiang, C.J., Salanitro, J.P., Chai, E.Y., Colthart, J.D., Klein, C.L., 1989. Aerobic biodegradation of benzene, toluene, and xylene in a sandy aquifer — data analysis and computer modeling. Ground Water 27 (6), 823-834.

Cozzarelli, I.M., Eganhouse, R.P., Baedecker, M.J., 1990. Transformation of monoaromatic hydrocarbons to organic acids in anoxic ground-water environment. Environ. Geol. Water Sci. 16 (2), 135-141.

Cozzarelli, I.M., Bekins, B.A., Baedecker, M.J., Aiken, G., Eganhouse, R.P., Tuccillo, M.E., 2001. Progression of natural attenuation processes at a crude oil spill site: II. Geochemical evolution of the plume. J. Contam. Hydrol. 53, 369-385.

Delin, G.N., Herkelrath, W.N., 1999. Long-term monitoring of unsaturated-zone properties to estimate recharge at the Bemidji crude-oil spill site. In: Morganwalp, D.W., Buxton, H.T. (Eds.), U.S. Geological Survey Toxic Substances Hydrology Program-Proceedings of the technical meeting, Charleston, South Carolina, March 8-12, 1999. U.S. Geol. Surv. Water-Resour. Invest., vol. 99-4018C, pp. 143-151.

Dillard, L.A., Blunt, M.J., 2000. Development of a pore network model to study nonaqueous phase liquid dissolution. Water Resour. Res. 36 (2), 439-454.

Dillard, L.A., Essaid, H.I., Herkelrath, W.N., 1997. Multiphase flow modeling of a crude-oil spill site with a bimodal permeability distribution. Water Resour. Res. 33 (7), 1617-1632.

Dillard, L.A., Essaid, H.I., Blunt, M.J., 2001. A functional relation for field-scale nonaqueous phase liquid dissolution developed using a pore network model. J. Contam. Hydrol. 48, 89-119.

Eganhouse, R.P., Dorsey, T.F., Phinney, C.S., Westcott, S., 1993a. Determination of C6-C10 aromatic hydrocarbons in water by purge-and-trap capillary gas chromatography. J. Chromatogr. 628, 81-92.

Eganhouse, R.P., Baedecker, M.J., Cozzarelli, I.M., Aiken, G.R., Thorn, K.A., Dorsey, T.F., 1993b. Crude oil in a shallow sand and gravel aquifer: II. Organic geochemistry. Appl. Geochem. 8, 551-567.

Eganhouse, R.P., Dorsey, T.F., Phinney, C.S., Westcott, A.M., 1996. Processes affecting the fate of monoaromatic hydrocarbons in an aquifer contaminated by crude oil. Environ. Sci. Technol. 30, 3304-3312.

Essaid, H.I., Herkelrath, W.N., Hess, K.M., 1993. Simulation of fluid distributions observed at a crude-oil spill site incorporating hysteresis, oil entrapment, and spatial variability of hydraulic properties. Water Resour. Res. 29 (6), $1753-1770$. 
Essaid, H.I., Bekins, B.A., Godsy, E.M., Warren, E., Baedecker, M.J., Cozzarelli, I.M., 1995. Simulation of aerobic and anaerobic biodegradation processes at a crude oil spill site. Water Resour. Res. 31 (12), $3309-3327$.

Essaid, H.I., Bekins, B.A., BIOMOC, 1997. A multispecies solute-transport model with biodegradation. U.S. Geol. Surv. Water-Resour., 97-4022.

Freeze, R.A., Cherry, J.A., 1979. Groundwater. Prentice-Hall, New Jersey.

Frind, E.O., Molson, J.W., Schirmer, M., Guiguer, N., 1999. Dissolution and mass transfer of multiple organics under field conditions: the Borden emplaced source. Water Resour. Res. 34 (3), 683-694.

Held, R.J., Celia, M.A., 2001. Pore-scale modeling and upscaling of nonaqueous phase liquid mass transfer. Water Resour. Res. 37 (3), 539-549.

Herkelrath, W.N., Delin, G.N., 2001. Long-term monitoring of soil-moisture in a harsh climate using reflectometer and TDR probes. In: Dowding, C.H. (Ed.), Proceedings of the Second International Symposium and Workshop on Time Domain Reflectometry for Innovative Geotechnical Applications, September 5-7, 2001. Northwestern University, Infrastructure Technology Institute, Evanston, IL, pp. 262-272.

Hess, K.M., Herkelrath, W.N., Essaid, H.I., 1992. Determination of subsurface fluid contents at a crude-oil spill site. J. Contam. Hydrol. 10, 75-96.

Hill, M.C., 1998. Methods and guidelines for effective model calibration. U.S. Geol. Surv. Water-Resour., $98-4005$.

Hult, M.F., 1984. Ground-water contamination by crude oil at the Bemidji, Minnesota, research site-an introduction. In: Hult, M.F. (Ed.), Ground-Water Contamination by Crude Oil at the Bemidji, Minnesota, Research Site. U.S. Geol. Surv. Water-Resour. Invest., vol. 84-4188, pp. 1-15.

Hult, M.F., Landon, M.K., Pfannkuch, H.O., 1991. Field validation of conceptual models of mobilization and transport of volatile petroleum derivatives in the unsaturated zone near Bemidji, Minnesota. In: Mallard, G.E., Aronson, D.A. (Eds.), U.S. Geological Survey Toxic Substances Hydrology Program-Proceedings of the Technical Meeting, Monterey, California, March 11-15, 1991. U.S. Geol. Surv. Water-Resour. Invest., vol. 91-4034, pp. 621-626.

Khachikian, C., Harmon, T.C., 2000. Nonaqueous phase liquid dissolution in porous media: Current state of knowledge and research needs. Transp. Porous Media 38, 3-28.

Konikow, L.F., Bredehoeft, J.D., 1978. Computer model of two-dimensional solute transport and dispersion in ground water. U.S. Geol. Surv. Tech. Water-Resour. Invest. (book 7, chap. C2).

Krumholz, L., Caldwell, M.E., Suflita, J.M., 1996. Biodegradation of "BTEX” hydrocarbons under anaerobic conditions. In: Crawford, R., Crawford, D. (Eds.), Bioremediation-Principles and Applications. Cambridge Univ. Press, Cambridge, UK, pp. 61-99.

Landmeyer, J.E., Chapelle, F.H., Bradley, P.M., 1996. Assessment of intrinsic bioremediation of gasoline contamination in the shallow aquifer, Laurel Bay Exchange, Marine Air Station Beaufort, South Carolina. U.S. Geol. Surv. Water-Resour., 96-4026.

Lovley, D.R., Baedecker, M.J., Lonergan, D.J., Cozzarelli, I.M., Phillips, E.J.P., Siegel, D.I., 1989. Oxidation of aromatic contaminants coupled to microbial iron reduction. Nature 339, 297-299.

Lu, G., Clement, T.P., Zheng, C., Wiedemeier, T.H., 1999. Natural attenuation of BTEX compounds: model development and field-scale application. Ground Water 37 (5), 707-717.

MacQuarrie, K.T.B., Sudicky, E.A., Frind, E.O., 1990. Simulation of biodegradable organic contaminants in groundwater: 1. Numerical formulation in principal directions. Water Resour. Res. 26 (2), 207-222.

Monod, J., 1949. The growth of bacterial cultures. Annu. Rev. Microbiol. 3, 371-394.

National Research Council, 2000. Natural Attenuation for Groundwater Remediation. National Academy Press, Washington, DC.

Parker, J.C., Islam, M., 2000. Inverse modeling to estimate LNAPL plume release timing. J. Contam. Hydrol. 45, $303-327$.

Parker, J.C., Lenhard, R.J., Kuppusamy, T., 1987. A parametric model for constitutive properties governing multiphase flow in porous media. Water Resour. Res. 23 (4), 618-624.

Poeter, E.P., Hill, M.C., 1998. Documentation of UCODE, a computer code for universal inverse modeling. U.S. Geol. Surv. Water-Resour., 98-4080.

Powers, S.E., Abriola, L.M., Weber, W.J., 1994. An experimental investigation of NAPL dissolution in saturated subsurface systems: transient mass transfer rates. Water Resour. Res. 30 (2), 321-332. 
Rifai, H.S., Bedient, P.B., Wilson, J.T., Miller, K.M., Armstrong, J.M., 1988. Biodegradation modeling at aviation fuel spill site. J. Environ. Eng. 114 (5), 1007-1029.

Schirmer, M., Butler, B.J., Roy, J.W., Frind, E.O., Barker, J.F., 1999. A relative-least-squares technique to determine unique Monod kinetic parameters of BTEX compounds using batch experiments. J. Contam. Hydrol. 37, 69-86.

Schirmer, M., Molson, J.W., Frind, E.O., Barker, J.F., 2000. Biodegradation modelling of a dissolved gasoline plume applying independent laboratory and field parameters. J. Contam. Hydrol. 46, 339-374.

Sciortino, A., Harmon, T.C., Yeh, W.W.-G., 2000. Inverse modeling for locating dense nonaqueous pools in groundwater under steady flow conditions. Water Resour. Res. 36 (7), 1723-1735

Seagren, E.A., Rittmann, B.E., Valocchi, A.J., 1993. Quantitative evaluation of flushing and biodegradation for enhancing in situ dissolution of nonaqueous-phase liquids. J. Contam. Hydrol. 12, 103-132.

Thierrin, J., Davis, G.B., Barber, C., Patterson, B.M., Pribac, F., Power, T.R., Lambert, M., 1993. Natural degradation rates of BTEX compounds and naphthalene in a sulphate reducing groundwater environment. Hydrol. Sci. J. 38 (4).

Vroblesky, D.A., Chapelle, F.H., 1994. Temporal and spatial changes of terminal electron-accepting processes in a petroleum hydrocarbon-contaminated aquifer and the significance for contaminant biodegradation. Water Resour. Res. 30 (5), 1561-1570.

Wiedemeier, T.H., Swanson, M.A., Wilson, J.T., Kampbell, D.H., Miller, R.N., Hansen, J.E., 1996. Approximation of biodegradation rate constants for monoaromatic hydrocarbons (BTEX) in ground water. Ground Water Monit. Remediat. 16, 186-194.

Yager, R.M., 2000. Simulated transport and biodegradation of chlorinated ethenes in a fractured dolomite aquifer near Niagara Falls, New York. U.S. Geol. Surv. Water-Resour., 00-4275.

Yang, Y., McCarty, P.L., 2002. Comparison between donor substrates for biologically enhanced tetrachloroethene DNAPL dissolution. Environ. Sci. Technol. 36, 3400-3404.

Zhu, J., Sykes, J.F., 2000. The influence of NAPL dissolution characteristics on field-scale contaminant transport in subsurface. J. Contam. Hydrol. 41, 133-154. 